\title{
Death Receptor 5 (TNFRSF10B) Is Upregulated and TRAIL Resistance Is Reversed in Hypoxia and Normoxia in Colorectal Cancer Cell Lines after Treatment with Skyrin, the Active Metabolite of Hypericum spp.
}

\author{
Marián Babinčák ${ }^{1}\left(\mathbb{D}\right.$, Rastislav Jendželovský ${ }^{1}\left(\mathbb{D}\right.$, Ján Košuth ${ }^{1} \mathbb{D}$, Martin Majerník $^{1}\left(\mathbb{D}\right.$, Jana Vargová ${ }^{1} \mathbb{D}$, \\ Kamil Mikulášek ${ }^{2,3}$, Zbyněk Zdráhal ${ }^{2,3}$ (D) and Peter Fedoročko ${ }^{1, *(\mathbb{D})}$ \\ 1 Institute of Biology and Ecology, Faculty of Science, Pavol Jozef Šafárik University in Košice, Šrobárova 2, \\ 04154 Košice, Slovakia; marian.babincak@upjs.sk (M.B.); rastislav.jendzelovsky@upjs.sk (R.J.); \\ jan.kosuth@upjs.sk (J.K.); martin.majernik@upjs.sk (M.M.); jana.vargova@upjs.sk (J.V.) \\ 2 Central European Institute of Technology, Masaryk University, Kamenice 5, 62500 Brno, Czech Republic; \\ 357352@mail.muni.cz (K.M.); zdrahal@sci.muni.cz (Z.Z.) \\ 3 National Centre for Biomolecular Research, Faculty of Science, Masaryk University, Kamenice 5, \\ 62500 Brno, Czech Republic \\ check for \\ * Correspondence: peter.fedorocko@upjs.sk; Tel.: +421-55-234-1182
} updates

Citation: Babincak, M.; Jendzelovsky, R.; Kosuth, J.; Majernik, M.; Vargova, J.; Mikulasek, K.; Zdrahal, Z.; Fedorocko, P. Death Receptor 5 (TNFRSF10B) Is Upregulated and TRAIL Resistance Is Reversed in Hypoxia and Normoxia in Colorectal Cancer Cell Lines after Treatment with Skyrin, the Active Metabolite of Hypericum spp. Cancers 2021, 13, 1646. https://doi.org/10.3390/ cancers 13071646

Academic Editors: Lisa M. Sedger and Heinrich Korner

Received: 17 December 2020

Accepted: 29 March 2021

Published: 1 April 202

Publisher's Note: MDPI stays neutral with regard to jurisdictional claims in published maps and institutional affiliations.

Copyright: (c) 2021 by the authors. Licensee MDPI, Basel, Switzerland. This article is an open access article distributed under the terms and conditions of the Creative Commons Attribution (CC BY) license (https:// creativecommons.org/licenses/by/ $4.0 /)$
Simple Summary: Hypoxic conditions are common in solid tumors and are very often connected with the poor prognosis of cancer patients. The lack of oxygen often causes the failure of therapy due to multiple mechanisms increasing cancer survival. Skyrin (SKR) is a secondary plant metabolite from the genus Hypericum spp., with a potential anticancer effects but still unknown mechanism of action. Based on our comprehensive analysis of SKR action, SKR shows significant efficiency against cancer, but not healthy cells, induces apoptosis, and upregulates Death receptor 5 in cancer cells in normoxic, as well as hypoxic conditions. SKR reverses TRAIL resistance even in TRAIL-resistant cancer cell lines in hypoxia. To sum up, SKR can be possibly used as a natural antitumor drug per se or as an adjuvant to TRAIL treatment in hypoxic and therapy-resistant tumors.

Abstract: Skyrin (SKR) is a plant bisanthraquinone secondary metabolite from the Hypericum genus with potential use in anticancer therapy. However, its effect and mechanism of action are still unknown. The negative effect of SKR on HCT 116 and HT-29 cancer cell lines in hypoxic and normoxic conditions was observed. HCT 116 cells were more responsive to SKR treatment as demonstrated by decreased metabolic activity, cellularity and accumulation of cells in the G1 phase. Moreover, an increasing number of apoptotic cells was observed after treatment with SKR. Based on the LC-MS comparative proteomic data from hypoxia and normoxia (data are available via ProteomeXchange with the identifier PXD019995), SKR significantly upregulated Death receptor 5 (DR5), which was confirmed by real-time qualitative PCR (RT-qPCR). Furthermore, multiple changes in the Tumor necrosis factor-related apoptosis-inducing ligand (TRAIL)-activated cascade were observed. Moreover, the reversion of TRAIL resistance was observed in HCT 116, HT-29 and SW620 cell lines, even in hypoxia, which was linked to the upregulation of DR5. In conclusion, our results propose the use of SKR as a prospective anticancer drug, particularly as an adjuvant to TRAIL-targeting treatment to reverse TRAIL resistance in hypoxia.

Keywords: skyrin; hypoxia; colorectal cancer; proteomics; Death receptor 5; TRAIL; TRAIL resistance; Hypericum

\section{Introduction}

Skyrin (SKR; CAS No. 602-06-2; PubChem CID: 73071; $\mathrm{C}_{30} \mathrm{H}_{18} \mathrm{O}_{10}$; molecular weight: $538.5 \mathrm{~g} / \mathrm{mol}$ ) is a plant secondary metabolite that is structurally very similar to hypericin. 
It is probably involved in hypericin synthesis $[1,2]$ or a molecule formed in parallel reactions [3]. It was first isolated from Penicillium islandicum in 1954 by Howard and Raistrick [4]. Later, it was isolated from many other fungi, lichens and plants [1,5-17]. It has a conformation of an emodin homodimer with a bisanthraquinone structure (Figure 1e) $[5,13,14,18]$.

a

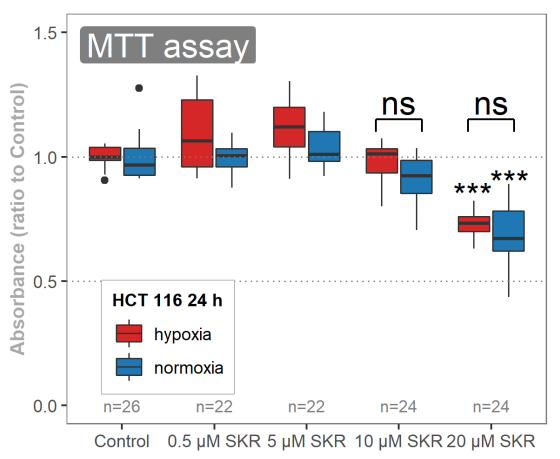

d

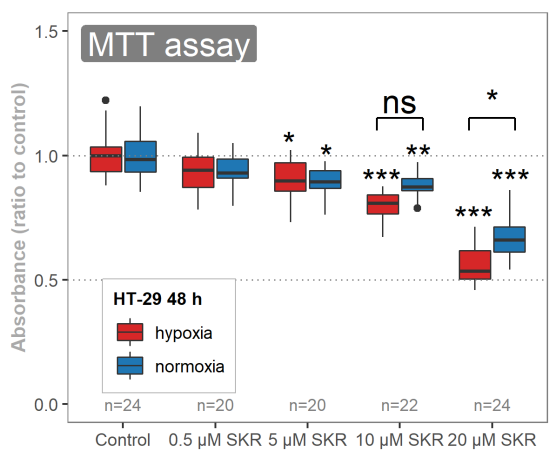

g

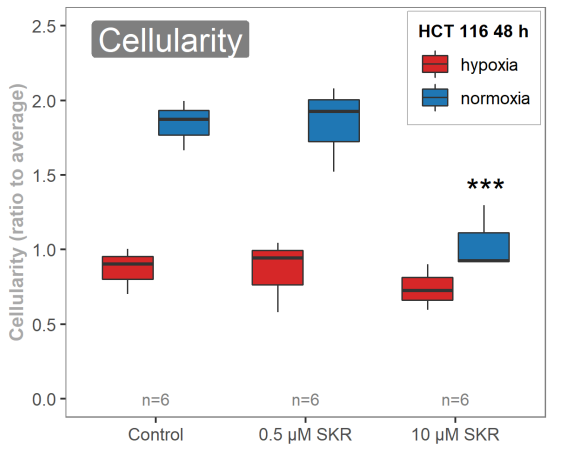

b

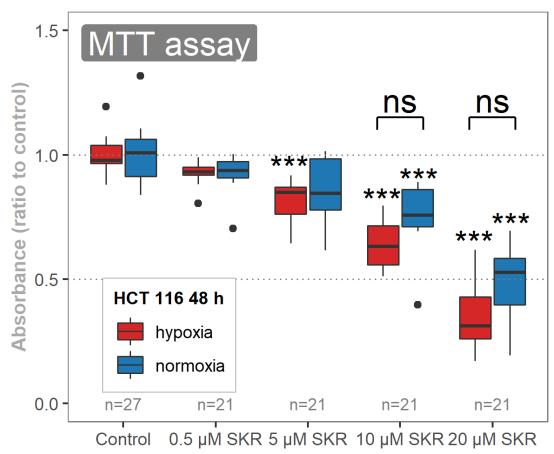

e

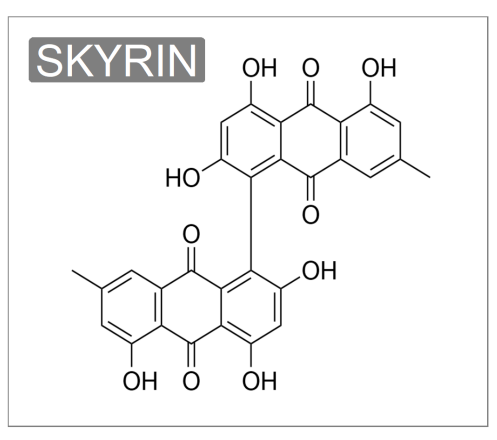

h

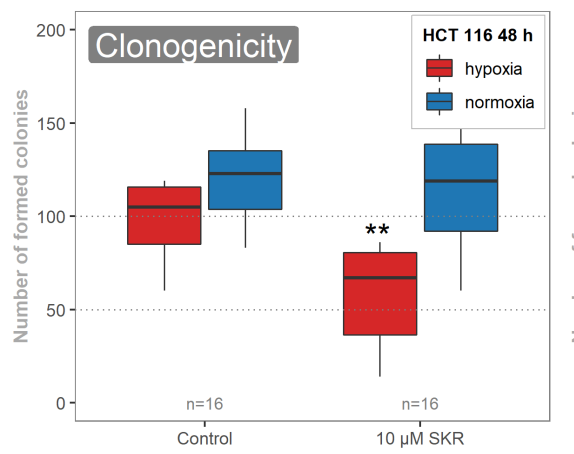

C

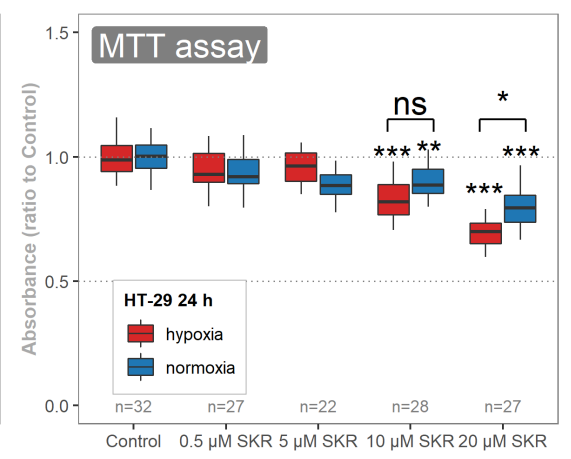

f

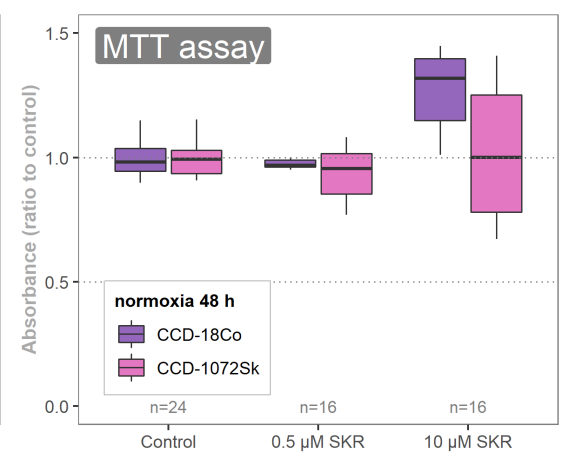

i

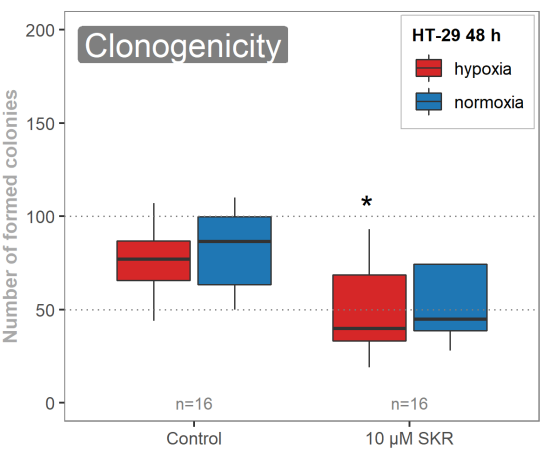

Figure 1. The effect of SKR on the basic cellular parameters of normal and cancer cell lines. (a-e) SKR significantly decreases the metabolic activity of both cancer cell lines, with the most prominent effect in HCT 116 cells, but with no effect on healthy cells. (a,b) In cancer cell line HCT 116, there was a significant effect after treatment with SKR, as observed in the $5 \mu \mathrm{M}$ concentration of SKR in hypoxic conditions and $10 \mu \mathrm{M}$ concentration of SKR in normoxic conditions after $48 \mathrm{~h}$. (c,d) In HT-29 cells, the effect of SKR on metabolic activity was significant in higher concentrations, as observed in HCT 116 cell line. (e) Molecule of skyrin (SKR). (f) SKR has no negative effect on the metabolic activity of pathologically unchanged cell lines in used concentrations. (g) The relative cellularity in treated samples of HCT 116 cell line in normoxia was significantly decreased, approximately to the levels of untreated cells in hypoxia. There were no significant changes in the cellularity of HCT 116 cell line after the treatment with SKR in hypoxia. (h,i) The clonogenicity of SKR treated cells was not increased towards the untreated samples. The results are expressed as boxplots of at least three independent experiments. The experimental groups were compared with the matching control group in the same condition (e.g., hypoxic control or normoxic control). The number of samples (n) is noted in plots. Comparison between hypoxia and normoxia samples is denoted over the compared samples $\left({ }^{*} p<0.05,{ }^{* *} p<0.01,{ }^{* * *} p<0.001\right)$, ns-not significant) 
The biological activity of SKR has been studied at several levels, from the inhibition of viral enzymes [6], through antimicrobial activity against Gram-negative and Gram-positive bacteria $[19,20]$ to cytotoxic activity against several cell lines $[8,11,12,16,21]$. However, the mechanism of action of SKR is not fully understood. Kiyoshi et al. attributed the cytotoxic activity of SKR on mouse lymphocytic leukemia cell line L1210 to impaired adenosine triphosphate (ATP) synthesis in mitochondria [5]. There was also observed DNA fragmentation with higher concentrations of SKR in the HL-60 cell line [8]. SKR also interacts with casein kinase, estrogen receptor, dopamine beta-hydroxylase and glucagon receptor [22]. Moreover, ${ }^{131}$ I labeled SKR showed selective accumulation in necrotic tissue comparable to hypericin that makes it a suitable candidate as a radioisotopic drug in the therapy of solid tumors [21]. This feature of SKR could be particularly interesting regarding solid tumors, which often possess a necrotic core that is closely related to the hypoxic area. Thus, SKR could preferentially accumulate and affect hypoxic cells that are related to the chemoresistant and invasive phenotype. Many plant secondary metabolites from the Hypericum genus are used in the treatment of different types of cancer, although they are related to various side effects, as reviewed in $[23,24]$.

Based on this, the interaction of SKR with biomolecules in hypoxic tissue, as well as the effect of SKR alone on those tumor cells that adapted to reduced oxygen, could be potentially interesting. Hypoxia is a condition in which a reduced oxygen content below a critical value is associated with the reduced function of organs and tissues [25-27]. In solid tumors, hypoxic conditions occur for several reasons, in particular due to the increased distance of the cells from the oxygen source, to structural abnormalities of the tumor vasculature or to decreased microcirculation within a solid tumor $[25,26,28]$.

From the molecular point of view, cells in hypoxia undergo significant changes. The main reason is the elevated activity of the HIF-1 (hypoxia-inducible factor 1) complex as a result of the coupling of oxygen-sensitive subunit HIF-1 $\alpha$ with HIF-1 $\beta$ [29,30]. HIF-1 regulates the expression of many genes involved in cell survival [26,28,31,32]. In cancer, HIF-1 activity is connected to angiogenesis, cell proliferation, metabolic adaptation or invasion and metastasis [33]. Many other processes are also regulated by HIF transcription factors, especially those related to drug resistance or treatment failure [33-35].

Death receptor 5 (DR5), known as Tumor necrosis factor-related apoptosis-inducing ligand (TRAIL) receptor 2 or Tumor necrosis factor receptor superfamily 10B or CD262 (DR5, TRAILR2 or TNFRSF10B; UniProt reference O14763) is a surface receptor that binds TRAIL and mediates apoptosis [36-39]. Moreover, HIF-2 $\alpha$ can act as a promoter of DR5 expression [40]. However, TRAIL-promoted apoptosis is attenuated in hypoxia [41,42]. Many drugs with a similar chemical structure to SKR upregulate DR5 [43-47], but the mechanism is still unknown. In our study, we chose the colorectal cancer cell line, which represents a model of rapidly expanding cancer cells forming hypoxic central regions within the solid mass $[48,49]$. Hypoxia is also coupled with a poor prognosis to TRAILmediated treatment in cancer patients $[41,42,50]$. The lack of oxygen in combination with the increase of anti-apoptotic Bcl-2 (B-cell lymphoma 2 protein) attenuates TRAIL-mediated therapy in hypoxic conditions $[41,42,51]$. Thus, the sensitization of hypoxic tumors to TRAIL-mediated treatment represents a propsective anticancer strategy.

\section{Results}

2.1. SKR Selectively Decreases the Metabolic Activity of Cancer Cells and Their Clonogenic Ability in Hypoxia

Our first aim was to determine the effect of SKR on the metabolic activity of cancer cell lines and to determine the effective concentration for further experiments to observe a moderate effect of SKR. We observed a significant decrease in metabolic activity in both cancer cell lines treated with SKR, even after the shorter incubation period $(24 \mathrm{~h})$ and in both cultivation conditions based on the decreased amount of formed formazan from the MTT assay. Calculated concentrations causing a 25\% decrease of metabolic activity based on the MTT assay are shown in Table 1. 
Table 1. SKR concentration resulting in a $25 \%$ decrease of metabolic activity based on MTT assay for cancer cell lines. Values are presented as concentrations in $\mu \mathrm{M}$ with standard deviation (SD) values for all used times and conditions.

\begin{tabular}{ccccc}
\hline & 24 h Normoxia & 24 h Hypoxia & 48 h Normoxia & 48 h Hypoxia \\
\hline HCT 116 & $17.88 \pm 1.56$ & $21.96 \pm 2.19$ & $9.50 \pm 0.80$ & $6.70 \pm 0.34$ \\
HT-29 & $25.67 \pm 2.80$ & $16.45 \pm 1.17$ & $15.83 \pm 1.15$ & $11.36 \pm 0.65$ \\
\hline
\end{tabular}

However, we observed some differences in the SKR effect on the metabolic status of cells, as follows. The effect was more prominent (1) after a longer exposure of cells to SKR ( 24 vs. 48 h), (2) in hypoxic compared to normoxic conditions and (3) in HCT 116 cell line compared to HT-29 (Figure 1a-d). Based on the results, the concentration of SKR for further experiments was set to $10 \mu \mathrm{M}$.

To assess the effect of SKR on healthy cells, human fibroblast cells from the colon (CCD18-Co) and foreskin (CCD-1072Sk) cultivated in normoxic conditions were used. In contrast to cancer cells, there was no decrease of metabolic activity after SKR treatment in CCD18-Co and CCD-1072Sk cell lines, not even after prolonged exposure (48 h; Figure 1f).

After this, we intended to determine the possible effect of SKR on the total cellularity (the total number of cells) and size of cells. There were no significant changes in the size of cells based on treatment, oxygen content or cultivation period $(14.1 \pm 0.57 \mu \mathrm{m}$ in HCT 116 and $15.3 \pm 0.80 \mu \mathrm{m}$ in HT-29, Figure S1). The inhibitory effect of hypoxia on cellularity was observed in both cell lines after $48 \mathrm{~h}$; in cell line HCT 116, there was also a minor effect after $24 \mathrm{~h}$. The significant inhibitory effect of SKR on cellularity was noticed only in HCT 116 cells in normoxia after prolonged treatment. In hypoxic conditions, no changes were observed between treated and untreated samples (Figure 1g and Figure S2). To finalize the complete picture of SKR effects on the basic parameters of cancer cells, the measurement of clonogenic ability was performed. As shown in Figure 1h,i, SKR does not affect the capability of cancer cells to form colonies under normoxia. However, when applied in hypoxia, a significant decrease in the total number of formed colonies was observed in both cancer cell lines (Figure 1i).

\subsection{SKR Increases the Accumulation of Cells in G1 Phase and Induces Apoptosis}

To look deeper into the potential mechanism action of SKR, we performed flow cytometry analysis to detect the potential incidence of apoptosis and necrosis in cells after treatment with SKR.

As shown in Figures 2i,j, SKR significantly increased the number of apoptotic cells in HCT 116 cell line after $48 \mathrm{~h}$ simultaneously with a decreasing number of live cells. Moreover, this effect was more remarkable in hypoxia than in normoxia. Furthermore, a smaller, nonsignificant increase in the number of apoptotic cells was observed in HT-29 cells treated for $48 \mathrm{~h}$ in hypoxia (Figure S3d). Representative FACS plots are shown in Figure $2 \mathrm{a}-\mathrm{h}$, and primary FACS data with backgating are presented in the Supplementary Materials (Figures S6-S29).

Finally, to determine the potential effect of SKR on the cell cycle distribution in cancer cells, the samples were stained with PI, and the amount of DNA was evaluated by flow cytometry. Significant changes in the distribution of individual phases of the cell cycle were observed only in HCT 116 cell line. After treatment with SKR under hypoxia, there was an increased number of cells in the G1 phase after $24 \mathrm{~h}$ (35.80\% $\pm 2.29 \%$ compared to $28.28 \%$ $\pm 2.31 \%$ in hypoxic control). This effect was more pronounced after prolonged exposure to SKR (48 h) not only in hypoxic (from $58.96 \% \pm 0.98 \%$ in control to $67.02 \% \pm 1.38 \%$ in $10 \mu \mathrm{M}$ SKR samples) but also under normoxic conditions (from $59.35 \% \pm 4.65 \%$ in control to $64.87 \% \pm 2.19 \%$ in $10 \mu \mathrm{M}$ SKR samples) (Figure 3 and Figure 54 ). 
a

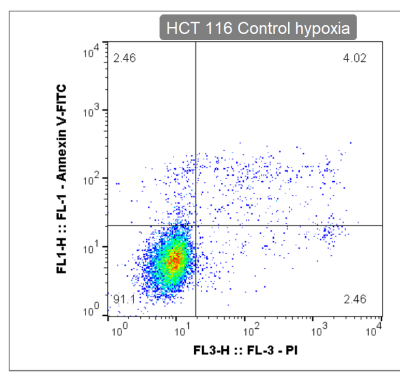

e

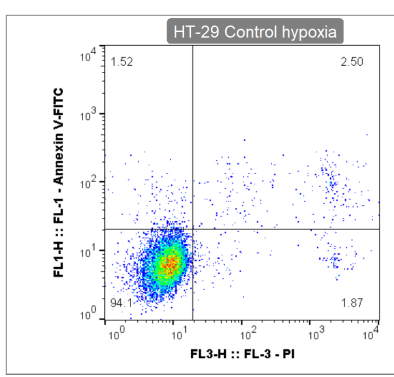

b

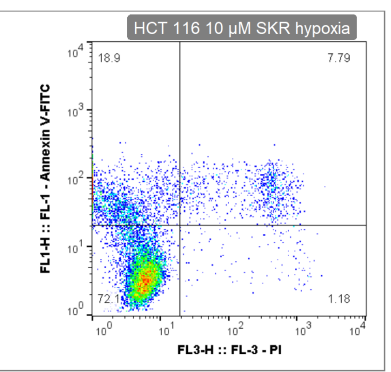

f

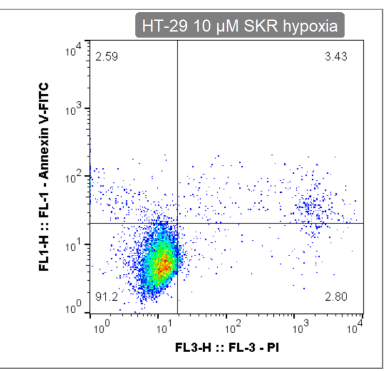

C

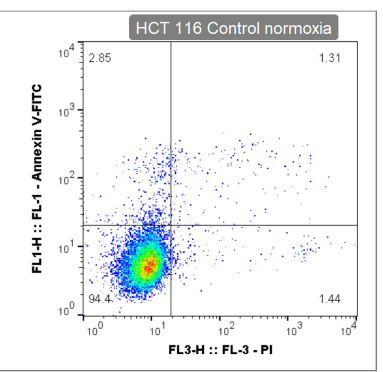

g

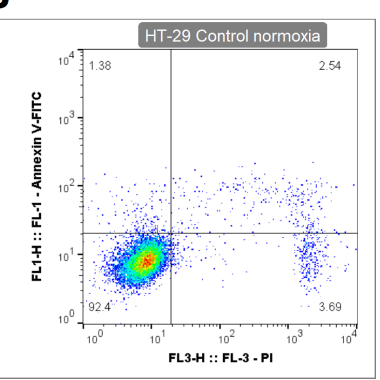

d

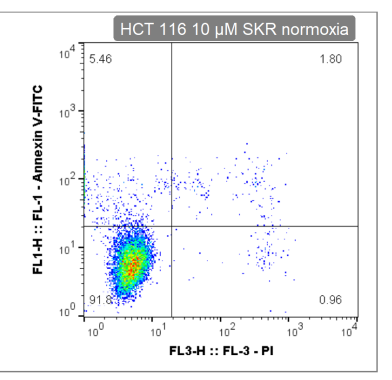

h

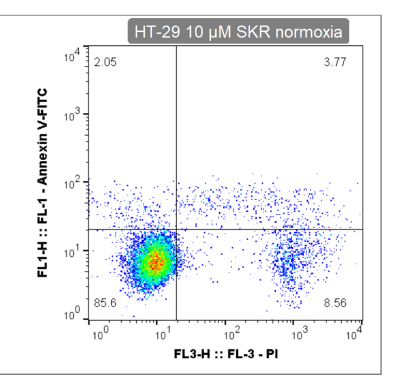

i
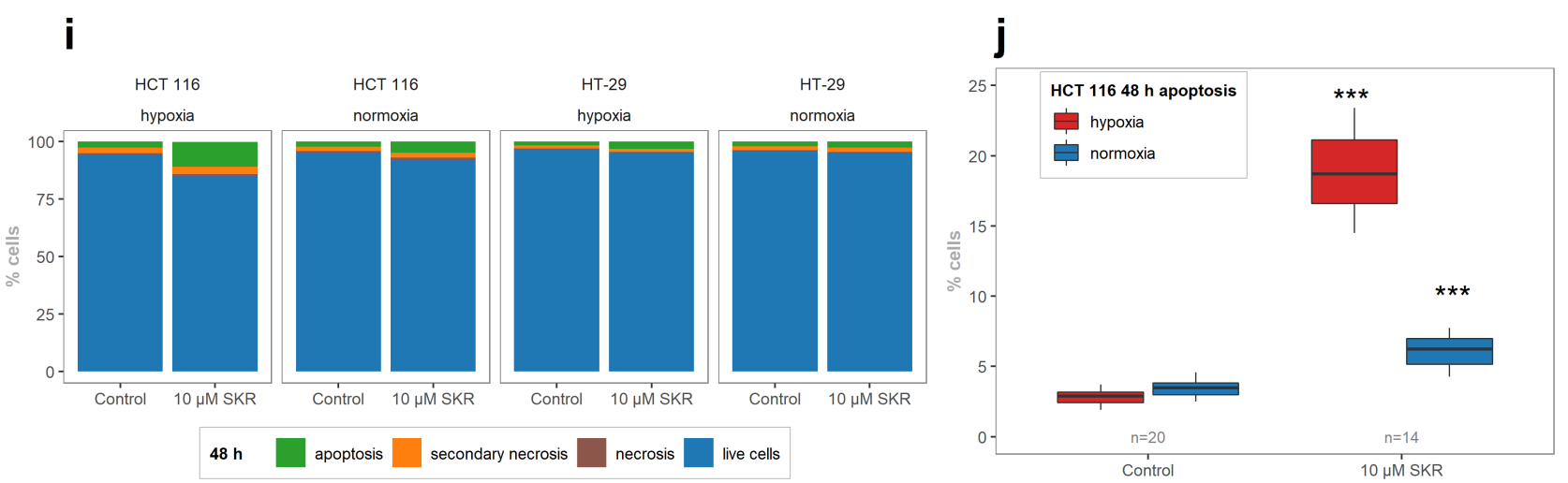

Figure 2. The effect of SKR on phosphatidylserine externalization in cancer cell lines HCT 116 and HT-29. (a-h) Representative FACS plots of debris-free singlets after SKR treatment in HCT 116 and HT-29 cell lines. (i) Ratios between the numbers of cells in gates stained with Annexin-V and PI as an average of at least three independent experiments. (j) Significantly increased number of apoptotic cells after treatment with SKR after $48 \mathrm{~h}$ in HCT 116 cell line. Control samples contain the same amount of DMSO as the sample with SKR. The results are expressed in boxplots or as average in bar plots of three independent experiments. The experimental groups were compared with the control group. The number of samples $(\mathrm{n})$ is noted in plots. $(* * *<0.001)$.

a

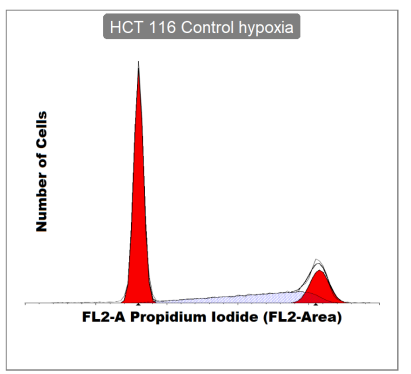

b

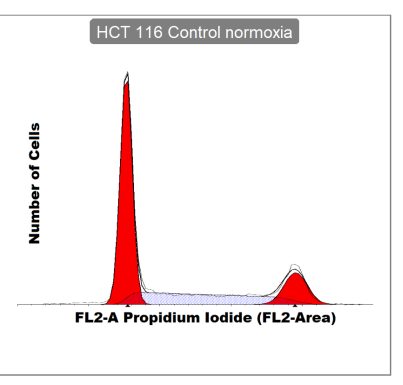

c

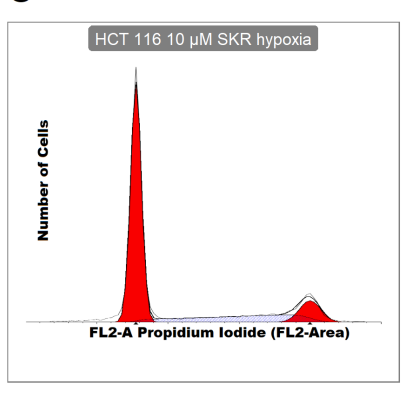

d

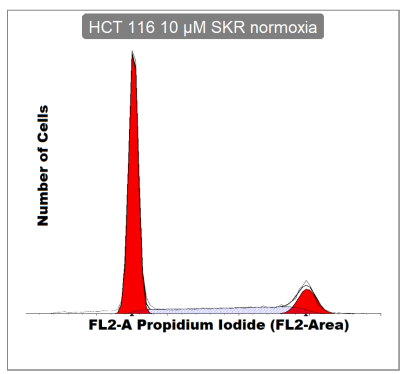

Figure 3. Cont. 
e

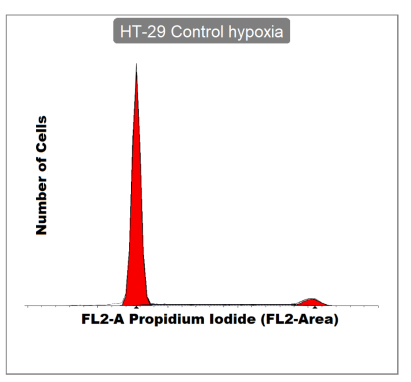

i $\mathbf{f}$

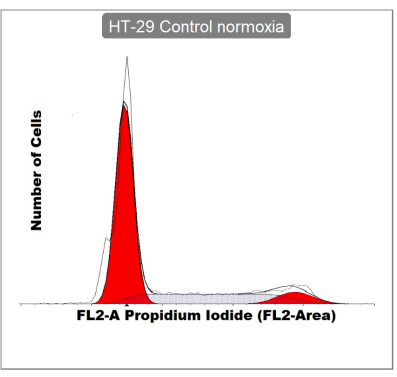

g

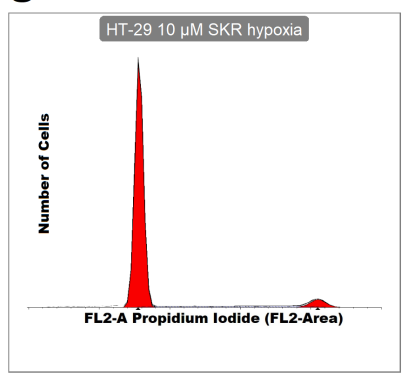

h

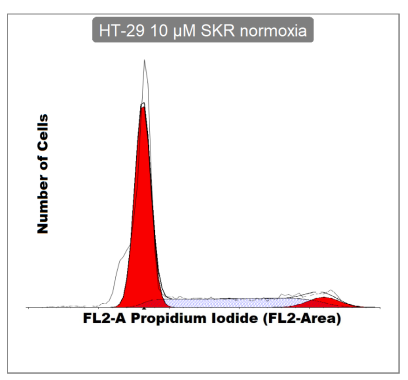

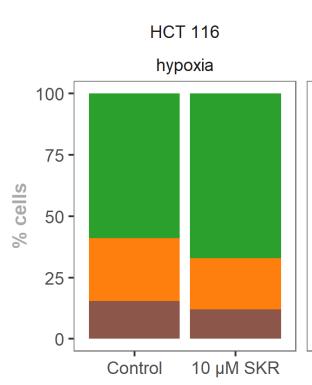
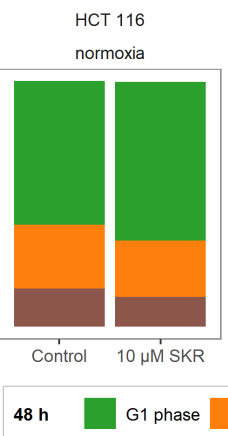
hypoxia

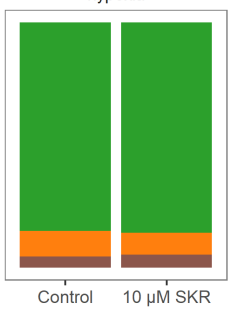

Sphase G2 phase
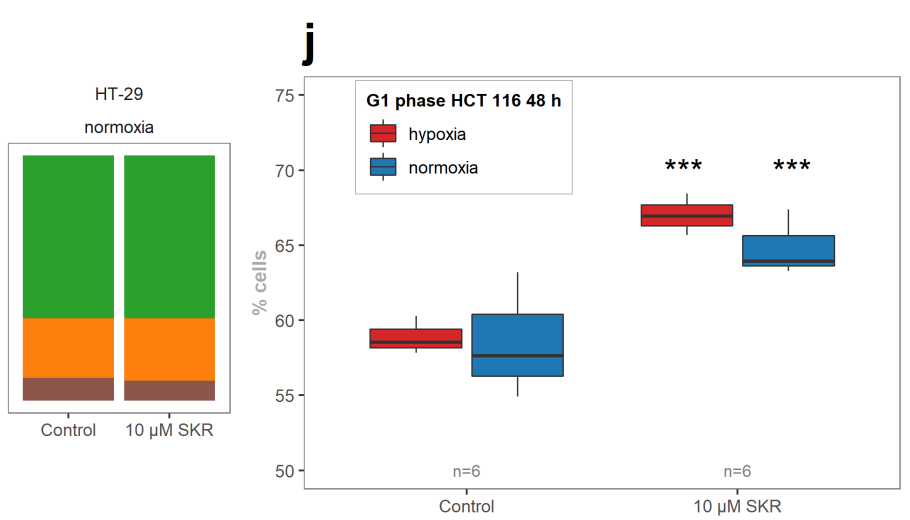

Figure 3. The effect of SKR on cell cycle distribution in cancer cell lines HCT 116 and HT-29. (a-h) Representative plots of cell cycle analysis after SKR treatment in HCT 116 and HT-29 cell lines. (i) Distributions of individual phases of the cell cycle analyzed after $48 \mathrm{~h}$ after treatment in HCT 116 and HT-29 cell line from at least three independent experiments. (j) Significant accumulation of HCT 116 cells in the G1 phase after $48 \mathrm{~h}$ after treatment with $10 \mu \mathrm{M}$ SKR. Control samples contain the same amount of DMSO as the sample with SKR. The results are expressed in boxplots or as averages in bar plots of three independent experiments. The experimental groups were compared with the control group. The number of samples (n) is noted in plots. $\left({ }^{* * *} p<0.001\right)$.

\subsection{SKR Upregulates Pathways Associated with Mitophagy and TRAIL Signalization}

Since there is little known about the molecular basis of the action of SKR on cells in general, we employed comparative proteomics to reveal changes in the proteome. Due to the different actions of SKR on both employed cancer cell lines, the more sensitive HCT 116 cells and a $10 \mu \mathrm{M}$ concentration of SKR with a more powerful effect were used. The whole proteome was measured and analyzed as described in Section 4. In total, 4974 protein groups containing 50,783 peptides were successfully identified from 1,128,203 MS/MS spectra of trypsin-digested samples. Based on the fact that all compared samples were collected at the same time after comparable treatment, Pearson's correlation coefficients were higher than 0.94 in all pairs (Figure 4a), but with notably higher correlations within the samples from hypoxia than from normoxia. The protein group intensities were normalized, and Log2FC values between groups of samples for each protein group were calculated. For the threshold for the rating of the protein group to be significant, the adjusted $p$ value for the difference between treated and untreated samples must be lower than 0.05 simultaneously in both hypoxia and normoxia. The threshold for changed regulation was set as Log2FC > +1.0 for upregulation and $\log 2 \mathrm{FC}<-1.0$ for downregulation simultaneously or +1.5 and -1.5 for particular analysis (Figure $4 b, c$ ).

We identified 508 significantly changed protein groups in hypoxia, 801 protein groups in normoxia and 158 significantly changed protein groups in both conditions simultaneously. The numbers of upregulated protein groups after SKR treatment were 66 and 61 for hypoxia and normoxia, respectively, and the numbers of downregulated protein groups after SKR treatment were 82 and 72 for hypoxia and normoxia, respectively. In both conditions simultaneously, there were seven upregulated and eight downregulated 
protein groups with a Log2FC level over +1.5 or below -1.5 . A list of upregulated and downregulated protein groups with Log2FC and relative abundancy is shown in Figure 4d. In Table 2, the list of all significantly upregulated and downregulated proteins is presented. The list of all identified protein groups with intensities and Log2FC within samples is provided in List of all identified protein groups (Data S1) in the Supplementary Materials.

a

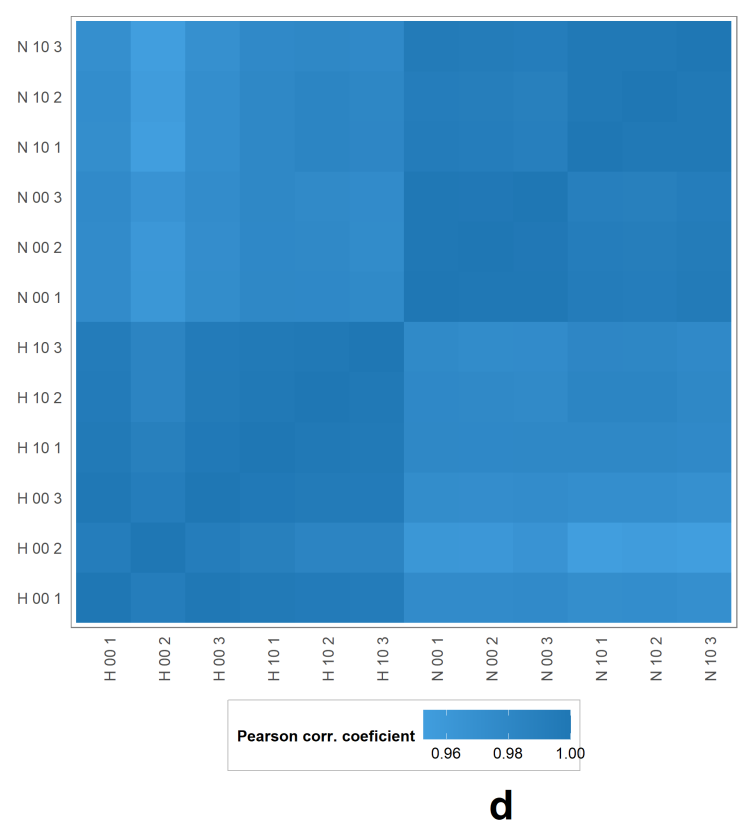

b

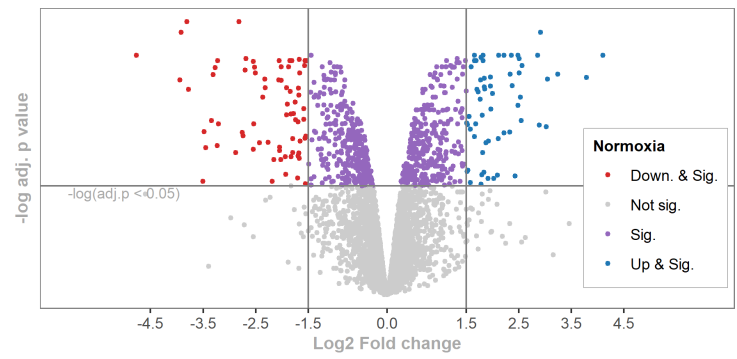

C

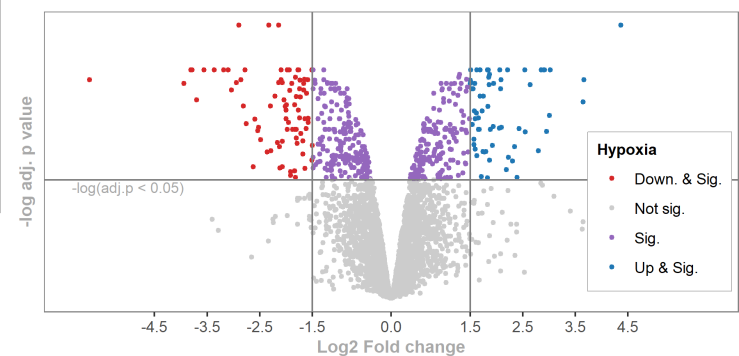

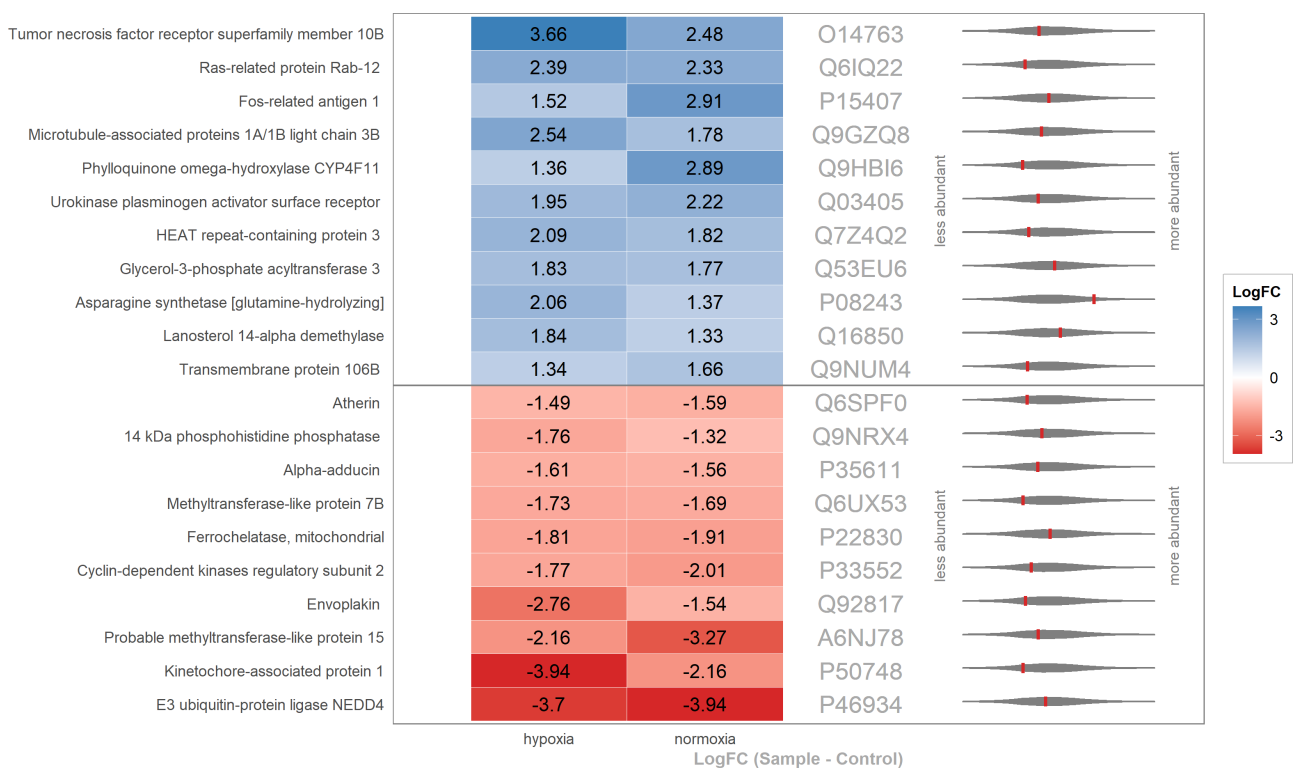

Figure 4. Result from the mass spectrometry (MS) analysis of the HCT 116 cells after $48 \mathrm{~h}$ treatment with $10 \mu \mathrm{M} \mathrm{SKR}$. (a) Heatmap of all calculated Pearson's correlation coefficients within all samples (hypoxia is marked by H, normoxia by N and 00 and 10 are control and $10 \mu \mathrm{M}$ SKR samples, respectively). The last number (1-3) indicates the specific repetition. $(\mathbf{b}, \mathbf{c})$ Volcano plots of all protein groups in the samples as a comparison between control and treated samples in hypoxia and normoxia, respectively. On $\mathrm{x}$ axes are the Log2 Fold change values of protein groups between control and $10 \mu \mathrm{M}$ SKR samples. The threshold for the significance of the protein group is an adj.p value lower than 0.05. (d) Heatmap of significantly upregulated (blue) and downregulated (red) protein groups in both conditions (hypoxia on the left and normoxia on the right) with UniProt accession numbers. Red lines in violin plots of all protein group intensity distributions represent the relative abundance of a protein group (more abundant on right). 


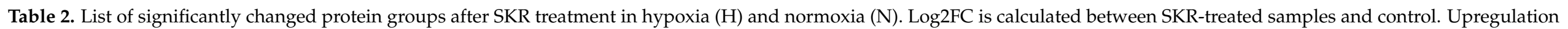
and downregulation labels: $\uparrow \log 2 \mathrm{FC} \geq+1.5$ (upregulated); $\downarrow$ Log2FC $\leq-1.5$ (downregulated).

\begin{tabular}{|c|c|c|c|c|c|c|c|}
\hline Accession & Description of Protein Group (Gene Name) & $\begin{array}{l}\log 2 F C \\
\text { (H) }\end{array}$ & $\begin{array}{l}\text { adj.p } \\
\text { Value (H) }\end{array}$ & $\begin{array}{l}\log 2 F C \\
(\mathrm{~N})\end{array}$ & $\begin{array}{l}\text { adj.p } \\
\text { Value (N) }\end{array}$ & Hypoxia & Normoxia \\
\hline O14763 & Tumor necrosis factor receptor superfamily member 10B (GN = TNFRSF10B) & 3.66 & 0 & 2.48 & 0.01 & $\uparrow$ & $\uparrow$ \\
\hline Q6IQ22 & Ras-related protein Rab-12 (GN = RAB12) & 2.39 & 0.05 & 2.33 & 0.01 & $\uparrow$ & $\uparrow$ \\
\hline Q9Y2H2 & Phosphatidylinositide phosphatase SAC2 (GN = INPP5F) & 3.65 & 0.01 & 1.05 & 0.03 & $\uparrow$ & \\
\hline P15407 & Fos-related antigen $1(\mathrm{GN}=$ FOSL1) & 1.52 & 0 & 2.91 & 0 & $\uparrow$ & $\uparrow$ \\
\hline Q9GZQ8 & Microtubule-associated proteins 1A/1B light chain 3B (GN = MAP1LC3B) & 2.54 & 0 & 1.78 & 0 & $\uparrow$ & $\uparrow$ \\
\hline Q9HBI6 & Phylloquinone omega-hydroxylase CYP4F11 (GN = CYP4F11) & 1.36 & 0.04 & 2.89 & 0.01 & & $\uparrow$ \\
\hline Q03405 & Urokinase plasminogen activator surface receptor (GN = PLAUR) & 1.95 & 0 & 2.22 & 0 & $\uparrow$ & $\uparrow$ \\
\hline Q7Z4Q2 & HEAT repeat-containing protein $3(\mathrm{GN}=$ HEATR3) & 2.09 & 0 & 1.82 & 0 & $\uparrow$ & $\uparrow$ \\
\hline Q53EU66 & Glycerol-3-phosphate acyltransferase $3(\mathrm{GN}=$ GPAT3) & 1.83 & 0.05 & 1.77 & 0 & $\uparrow$ & $\uparrow$ \\
\hline Q9BSH5 & Haloacid dehalogenase-like hydrolase domain-containing protein 3 (GN = HDHD3) & 3.01 & 0.01 & 0.44 & 0.02 & $\uparrow$ & \\
\hline P08243 & Asparagine synthetase [glutamine-hydrolyzing] (GN = ASNS) & 2.06 & 0 & 1.37 & 0 & $\uparrow$ & \\
\hline Q16850 & Lanosterol 14-alpha demethylase (GN = CYP51A1) & 1.84 & 0 & 1.33 & 0 & $\uparrow$ & \\
\hline Q9NUM4 & Transmembrane protein 106B (GN = TMEM106B) & 1.34 & 0.01 & 1.66 & 0.01 & & $\uparrow$ \\
\hline H3BU86 & STX16-NPEPL1 readthrough (NMD candidate) (GN = STX16-NPEPL1) & 1.8 & 0.02 & 1.18 & 0.05 & $\uparrow$ & \\
\hline Q8ND82 & Zinc finger protein $280 \mathrm{C}(\mathrm{GN}=\mathrm{ZNF} 280 \mathrm{C})$ & 1.86 & 0 & 1.06 & 0.01 & $\uparrow$ & \\
\hline Q9H6H4 & Receptor expression-enhancing protein 4 (GN = REEP4) & 1.84 & 0.01 & 0.98 & 0.04 & $\uparrow$ & \\
\hline O95352 & Ubiquitin-like modifier-activating enzyme ATG7 (GN = ATG7) & 1.56 & 0.01 & 1.11 & 0.02 & $\uparrow$ & \\
\hline Q8IVF2 & Protein AHNAK2 (GN = AHNAK2) & 1.93 & 0.02 & 0.7 & 0.05 & $\uparrow$ & \\
\hline O15231 & Zinc finger protein $185(\mathrm{GN}=$ ZNF185) & 1.51 & 0 & 1.09 & 0.05 & $\uparrow$ & \\
\hline Q9NQW6 & Anillin $(\mathrm{GN}=\mathrm{ANLN})$ & 0.52 & 0.04 & 1.84 & 0 & & $\uparrow$ \\
\hline Q9Y617 & Phosphoserine aminotransferase (GN = PSAT1) & 1.5 & 0 & 0.83 & 0 & $\uparrow$ & \\
\hline Q9NR12 & PDZ and LIM domain protein 7 (GN = PDLIM7) & 1.51 & 0 & 0.72 & 0.01 & $\uparrow$ & \\
\hline Q9NP97 & Dynein light chain roadblock-type 1 (GN = DYNLRB1) & -1.22 & 0.04 & 2.37 & 0 & & $\uparrow$ \\
\hline Q8N5M9 & Protein jagunal homolog $1(\mathrm{GN}=\mathrm{JAGN} 1)$ & -2.59 & 0.01 & 3.24 & 0 & $\downarrow$ & $\uparrow$ \\
\hline Q9NUQ3 & Gamma-taxilin (GN = TXLNG) & -0.91 & 0.02 & 1.52 & 0.01 & & $\uparrow$ \\
\hline P15153 & Ras-related C3 botulinum toxin substrate $2(\mathrm{GN}=\mathrm{RAC} 2)$ & 1.57 & 0.02 & -1.14 & 0.01 & $\uparrow$ & \\
\hline P14635 & G2/mitotic-specific cyclin-B1 (GN = CCNB1) & 1.86 & 0 & -1.45 & 0.04 & $\uparrow$ & \\
\hline Q9H2C0 & Gigaxonin $(\mathrm{GN}=\mathrm{GAN})$ & -2.48 & 0.02 & 2.43 & 0.04 & $\downarrow$ & $\uparrow$ \\
\hline Q9UL03 & Integrator complex subunit $6(\mathrm{GN}=$ INTS6) & -1.77 & 0 & 1.5 & 0 & $\downarrow$ & \\
\hline
\end{tabular}


Table 2. Cont

\begin{tabular}{|c|c|c|c|c|c|c|c|}
\hline Accession & Description of Protein Group (Gene Name) & $\begin{array}{l}\log 2 F C \\
\text { (H) }\end{array}$ & $\begin{array}{l}\text { adj.p } \\
\text { Value (H) }\end{array}$ & $\begin{array}{l}\log 2 \mathrm{FC} \\
(\mathrm{N})\end{array}$ & $\begin{array}{l}\text { adj.p } \\
\text { Value (N) }\end{array}$ & Hypoxia & Normoxia \\
\hline Q14BN4 & Sarcolemmal membrane-associated protein $(\mathrm{GN}=\mathrm{SLMAP})$ & 4.26 & 0.04 & -4.77 & 0 & $\uparrow$ & $\downarrow$ \\
\hline Q9HCS7 & Pre-mRNA-splicing factor SYF1 (GN = XAB2) & -1.79 & 0.02 & 0.65 & 0.04 & $\downarrow$ & \\
\hline P31483 & Nucleolysin TIA-1 isoform p40 (GN = TIA1) & 0.65 & 0.03 & -1.83 & 0.02 & & $\downarrow$ \\
\hline Q16555 & Dihydropyrimidinase-related protein 2 (GN = DPYSL2) & -0.46 & 0.03 & -1.53 & 0 & & $\downarrow$ \\
\hline P82664 & $28 \mathrm{~S}$ ribosomal protein $\mathrm{S} 10$, mitochondrial $(\mathrm{GN}=\mathrm{MRPS} 10)$ & -1.65 & 0 & -0.45 & 0.03 & $\downarrow$ & \\
\hline P55011 & Solute carrier family 12 member $2(\mathrm{GN}=\mathrm{SLC} 12 \mathrm{~A} 2)$ & -1.72 & 0.01 & -0.45 & 0.04 & $\downarrow$ & \\
\hline Q9P2R3 & Rabankyrin-5 (GN = ANKFY1) & -1.67 & 0.01 & -0.88 & 0.01 & $\downarrow$ & \\
\hline P00395 & Cytochrome $\mathrm{c}$ oxidase subunit $1(\mathrm{GN}=\mathrm{MT}-\mathrm{CO} 1)$ & -0.91 & 0.03 & -1.66 & 0 & & $\downarrow$ \\
\hline Q92466 & DNA damage-binding protein $2(\mathrm{GN}=\mathrm{DDB} 2)$ & -1.64 & 0.04 & -1.15 & 0.03 & $\downarrow$ & \\
\hline Q99UHL4 & Dipeptidyl peptidase $2(\mathrm{GN}=\mathrm{DPP} 7)$ & -1.68 & 0.03 & -1.12 & 0.03 & $\downarrow$ & \\
\hline Q9BRK5 & $45 \mathrm{kDa}$ calcium-binding protein $(\mathrm{GN}=\mathrm{SDF} 4)$ & -2.02 & 0.01 & -0.81 & 0 & $\downarrow$ & \\
\hline Q6SPF0 & Atherin $(\mathrm{GN}=\mathrm{SAMD} 1)$ & -1.49 & 0.03 & -1.59 & 0.01 & & $\downarrow$ \\
\hline Q9NRX4 & 14 kDa phosphohistidine phosphatase (GN = PHPT1) & -1.76 & 0 & -1.32 & 0.01 & $\downarrow$ & \\
\hline P14406 & Cytochrome c oxidase subunit 7A2, mitochondrial (GN = COX7A2) & -2.14 & 0 & -1.01 & 0 & $\downarrow$ & \\
\hline Q6UX53 & Methyltransferase-like protein 7B (GN = METTL7B) & -1.73 & 0 & -1.69 & 0 & $\downarrow$ & $\downarrow$ \\
\hline P22830 & Ferrochelatase, mitochondrial $(\mathrm{GN}=\mathrm{FECH})$ & -1.81 & 0.01 & -1.91 & 0.01 & $\downarrow$ & $\downarrow$ \\
\hline O94832 & Unconventional myosin-Id (GN = MYO1D) & -2.52 & 0.01 & -1.23 & 0.01 & $\downarrow$ & \\
\hline P33552 & Cyclin-dependent kinases regulatory subunit $2(\mathrm{GN}=\mathrm{CKS} 2)$ & -1.77 & 0.01 & -2.01 & 0 & $\downarrow$ & $\downarrow$ \\
\hline Q92817 & Envoplakin $(\mathrm{GN}=\mathrm{EVPL})$ & -2.76 & 0.01 & -1.54 & 0.01 & $\downarrow$ & $\downarrow$ \\
\hline A6NJ78 & Probable methyltransferase-like protein 15 (GN = METTL15) & -2.16 & 0.02 & -3.27 & 0 & $\downarrow$ & $\downarrow$ \\
\hline P50748 & Kinetochore-associated protein $1(\mathrm{GN}=\mathrm{KNTC} 1)$ & -3.94 & 0 & -2.16 & 0.02 & $\downarrow$ & $\downarrow$ \\
\hline Q14517 & Protocadherin Fat $1(\mathrm{GN}=$ FAT1 $)$ & -5.73 & 0 & -0.49 & 0.05 & $\downarrow$ & \\
\hline P46934 & E3 ubiquitin-protein ligase NEDD4 (GN = NEDD4) & -3.7 & 0.01 & -3.94 & 0 & $\downarrow$ & $\downarrow$ \\
\hline
\end{tabular}


After this, the analysis of affected pathways was performed using Reactome. Lists of significantly affected pathways are in Tables 3 and 4. Most of the significantly overrepresented pathways with upregulated proteins were coupled with two main processes: (1) the regulation of cell death and survival connected to TRAIL signaling or extrinsic apoptosis signaling via death receptors and (2) the degradation process of mitochondria. The results from the Reactome pathway analysis of significantly downregulated protein groups might be linked to (1) the downregulation of PTEN regulating proteins leading to the reduction of cell proliferation and apoptosis promotion and (2) pathways connected to the apoptotic process in the cell.

Table 3. List of pathways significantly connected to upregulated proteins. As the input for Reactome analysis, we used a list of all protein groups that were significantly changed (adj. $p$ value $<0.05$ ) between control and sample in both conditions and upregulated (Log2FC $>1$ ). Listed are 20 pathways with a higher $p$-value; each entity's $p$-value and FDR was calculated by the Reactome engine.

\begin{tabular}{|c|c|c|c|c|}
\hline Pathway Name & $\begin{array}{l}\text { Entities } \\
\text { Found }\end{array}$ & $\begin{array}{l}\text { Entities } \\
\text { Total }\end{array}$ & $\begin{array}{l}\text { Entities' } \\
p \text {-Value }\end{array}$ & $\begin{array}{l}\text { Entities' } \\
\text { FDR }\end{array}$ \\
\hline Rab regulation of trafficking & 2 & 123 & 0.00236 & 0.0398 \\
\hline Attachment of GPI anchor to uPAR & 1 & 7 & 0.00429 & 0.0398 \\
\hline TRAIL signaling & 1 & 8 & 0.0049 & 0.0398 \\
\hline Regulation by c-FLIP & 1 & 11 & 0.00674 & 0.0398 \\
\hline Dimerization of procaspase- 8 & 1 & 11 & 0.00674 & 0.0398 \\
\hline Receptor-mediated mitophagy & 1 & 11 & 0.00674 & 0.0398 \\
\hline Pexophagy & 1 & 11 & 0.00674 & 0.0398 \\
\hline TP53 regulates transcription of death receptors and ligands & 1 & 12 & 0.00735 & 0.0398 \\
\hline Dissolution of Fibrin Clot & 1 & 13 & 0.00796 & 0.0398 \\
\hline CASP8 activity is inhibited & 1 & 14 & 0.00857 & 0.0421 \\
\hline Caspase activation via death receptors in the presence of ligand & 1 & 19 & 0.0116 & 0.0421 \\
\hline Regulation of necroptotic cell death & 1 & 21 & 0.0128 & 0.0421 \\
\hline Pink/Parkin mediated mitophagy & 1 & 22 & 0.0134 & 0.0421 \\
\hline RIPK1-mediated regulated necrosis & 1 & 23 & 0.014 & 0.0421 \\
\hline Regulated necrosis & 1 & 23 & 0.014 & 0.0421 \\
\hline Mitophagy & 1 & 29 & 0.0177 & 0.0474 \\
\hline Caspase activation via extrinsic apoptotic signaling pathway & 1 & 29 & 0.0177 & 0.0474 \\
\hline Synthesis of PA & 1 & 39 & 0.0237 & 0.0474 \\
\hline NGF-stimulated transcription & 1 & 39 & 0.0237 & 0.0474 \\
\hline
\end{tabular}

\subsection{SKR Significantly Upregulates Death Receptor 5 in HCT 116 Cells in Hypoxia and Normoxia}

Based on the results of the comparative proteomic analysis of HCT 116 cell line treated with SKR in both conditions (normoxia and hypoxia), we assumed that the potential mechanism of SKR action could be based on upregulation of a protein known as Death receptor 5 (DR5; TNFRSF10B; UniProt reference O14763) encoded by the Tumor necrosis factor receptor superfamily 10B gene (TNFRSF10B). The level of protein was significantly upregulated in HCT 116 cells treated by SKR regardless of cell oxygenation (Figure 5a).

We also focused on the expression of other TRAIL and TNF-relevant proteins. Another TRAIL receptor-Death receptor 4 (DR4; TNFRSF10A; UniProt reference O00220) encoded by the Tumor necrosis factor receptor superfamily 10A gene (TNFRSF10A)-was significantly changed in hypoxia but not upregulated (Log2FC in hypoxia was 1.38, threshold for upregulation was +1.5 ; Figure $5 b$ ). In the expression of decoy receptor 3 (DcR3; TNFRSF6B; UniProt reference O95407) or FAS-associated death domain protein (FADD; UniProt reference Q13158), no significant changes were observed (Figure 5c,d). Neither TNF alpha, TNFR1 nor TNFR2 were identified by MS. 
Table 4. List of pathways significantly connected to downregulated proteins. As an input for Reactome analysis, we used a list of all protein groups that were significantly changed (adj. $p$ value $<0.05$ ) between the control and sample in both conditions and downregulated $(\log 2 \mathrm{FC}<-1)$. All pathways are listed; each entity's $p$-value and FDR was calculated by the Reactome engine.

\begin{tabular}{lllll}
\hline Pathway Name & $\begin{array}{l}\text { Entities } \\
\text { Found }\end{array}$ & $\begin{array}{l}\text { Entities } \\
\text { Total }\end{array}$ & $\begin{array}{l}\text { Entities' } \\
\boldsymbol{p} \text {-Value }\end{array}$ & $\begin{array}{l}\text { Entities' }^{\prime} \\
\text { FDR }\end{array}$ \\
\hline Regulation of PTEN localization & 1 & 9 & 0.0063 & 0.126 \\
Downregulation of ERBB4 signaling & 1 & 11 & 0.0077 & 0.126 \\
Caspase-mediated cleavage of cytoskeletal proteins & 1 & 12 & 0.00839 & 0.126 \\
Heme biosynthesis & 1 & 15 & 0.0105 & 0.126 \\
Miscellaneous transport and binding events & 1 & 26 & 0.0181 & 0.126 \\
Metabolism of porphyrins & 1 & 28 & 0.0195 & 0.126 \\
Apoptotic cleavage of cellular proteins & 1 & 38 & 0.0264 & 0.126 \\
XBP1(S) activates chaperone genes & 1 & 48 & 0.0332 & 0.126 \\
IRE1alpha activates chaperones & 1 & 50 & 0.0346 & 0.126 \\
Apoptotic execution phase & 1 & 52 & 0.0359 & 0.126 \\
Signaling by ERBB4 & 1 & 62 & 0.0427 & 0.126 \\
Regulation of PTEN stability and activity & 1 & 69 & 0.0474 & 0.126 \\
\hline
\end{tabular}

a

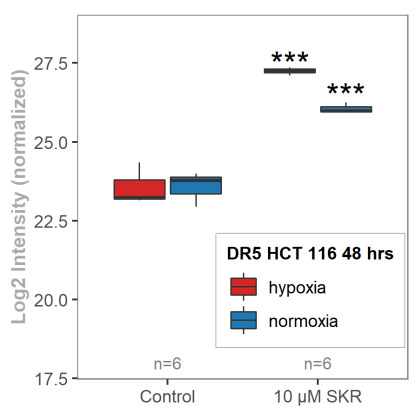

b

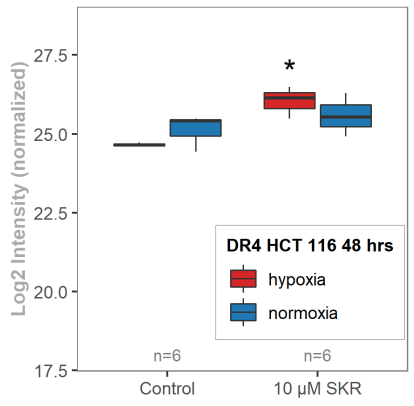

C

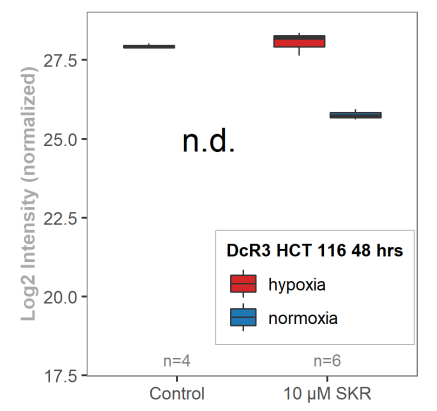

d

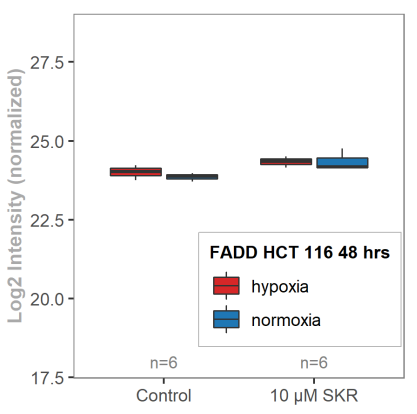

Figure 5. SKR after $48 \mathrm{~h}$ treatment of HCT 116 cells increases the expression of DR5 on protein level. Normalized log2 intensity of Death receptor 5 (DR5) protein (a), DR4 (b), DcR3 (c) and FAS-associated death domain protein (FADD) (d) evaluated by MS. The boxplots represent at least three independent experiments. DcR3 was not detected in normoxic control. The number of samples $(\mathrm{n})$ is noted in plots. The experimental groups were compared with the matching control group $\left(* p<0.05,{ }^{* * *} p<0.001\right)$. n.d.- not detected.

To determine if this upregulation of the DR5 protein by SKR was the result of the increased level of gene mRNA or solely protein stabilization (or some other posttranscriptional/posttranslational mechanism), RT-qPCR was performed. Consistent with proteomic analysis, we analyzed the expression of mRNA after $48 \mathrm{~h}$ incubation with SKR (in HCT 116 and HT-29 cell lines). We also considered the gene expression after 2 and $6 \mathrm{~h}$ to observe the kinetics of mRNA synthesis (TRAIL-resistant cell lines, HT-29 and SW620 cell lines, were employed for this purpose). The results presented in Figure $6 \mathrm{a}, \mathrm{d}$ show that in HCT 116 cell line, regardless of oxygen level, SKR significantly increased the level of the TNFRSF10B gene transcripts represented by the both alternatively spliced isoforms, the isoform 1 (Figure 6a) and the isoform 2 (Figure $6 \mathrm{~d}$ ), as shown by the gene expression after $48 \mathrm{~h}$. In HT-29 cell line, there was a significant increase in the TNFRSF10B mRNA level (in the both isoforms) after $48 \mathrm{~h}$ only in normoxia (Figure $6 \mathrm{~b}, \mathrm{e}$ ). On the contrary, incubation with SKR after $6 \mathrm{~h}$ showed the increased expression of TNFRSF10B (in both isoforms) in hypoxia (Figure $6 \mathrm{c}, \mathrm{f})$. A similar effect on TNFRSF10B gene expression after $6 \mathrm{~h}$ was found also in SW620 cell line (see Figure S5e; both isoforms were detected simultaneously). 
a

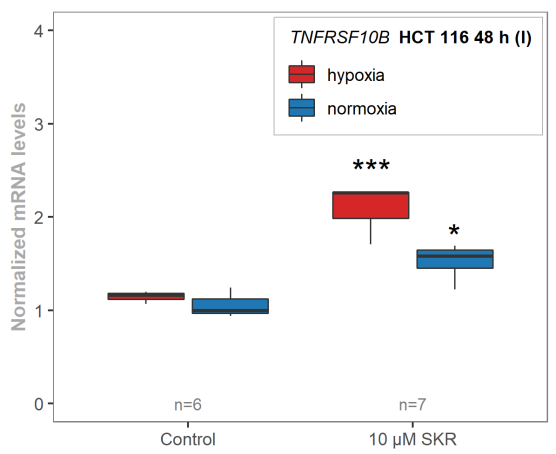

d

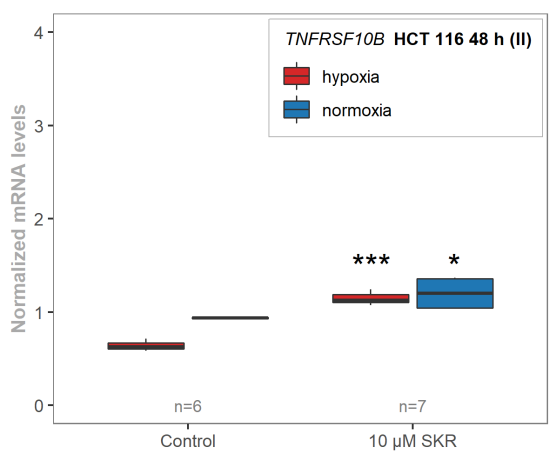

g

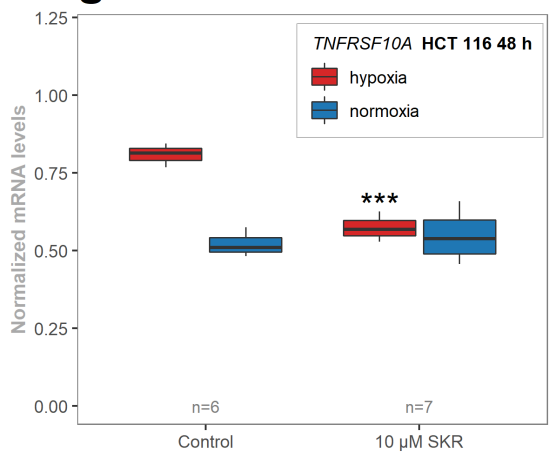

j

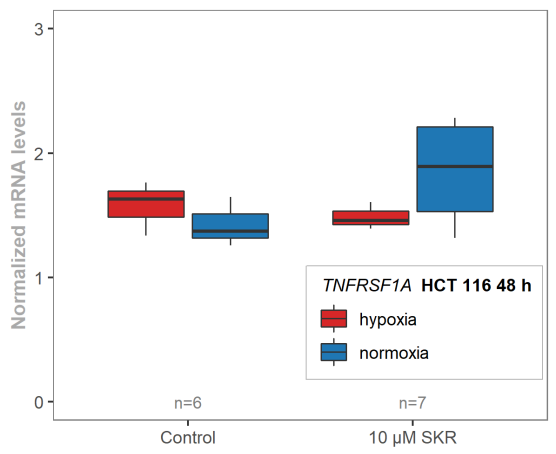

b

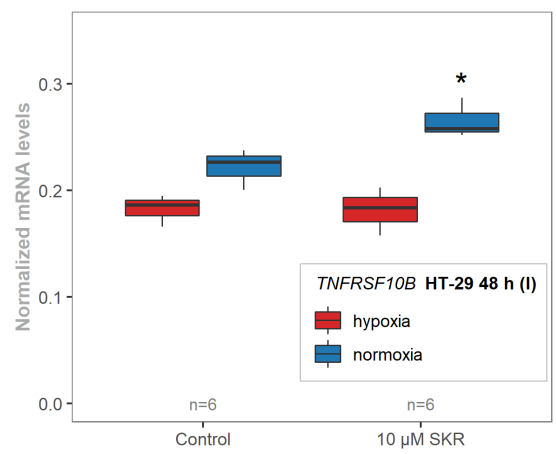

e

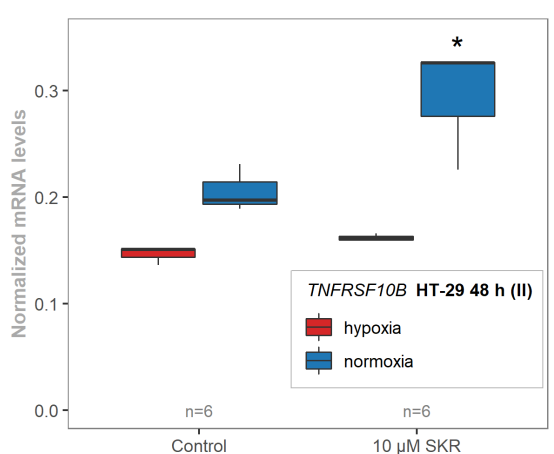

h

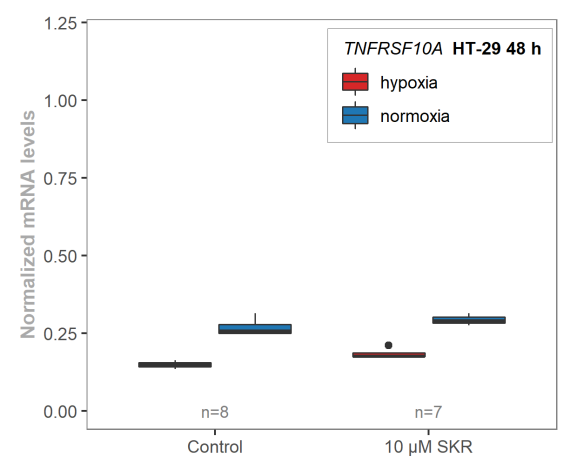

k

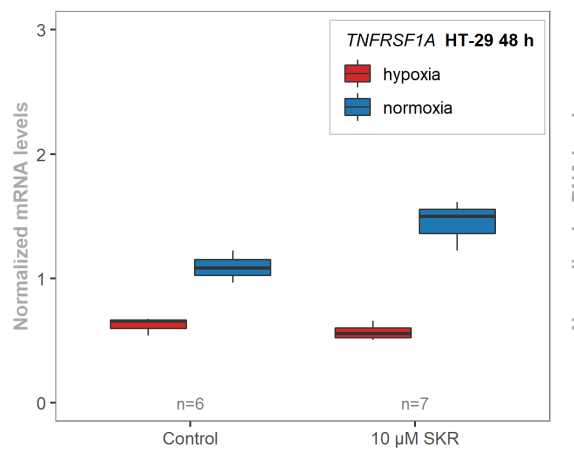

C

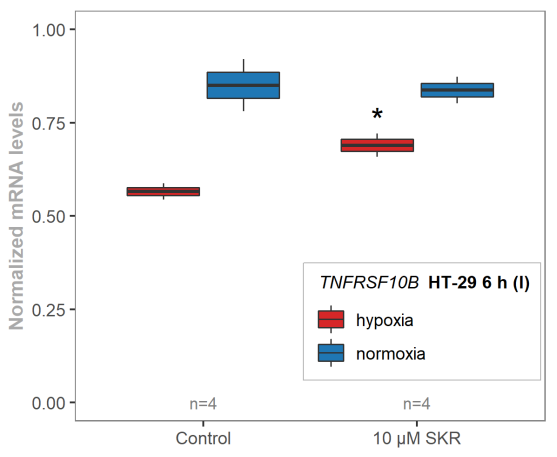

f

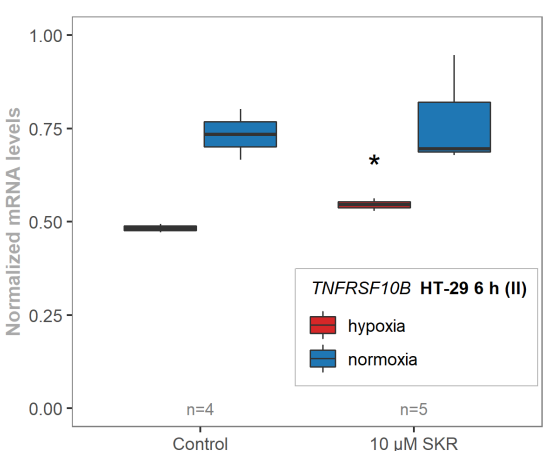

i

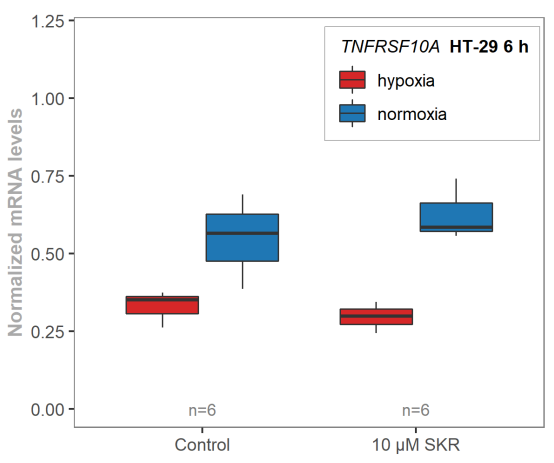

I

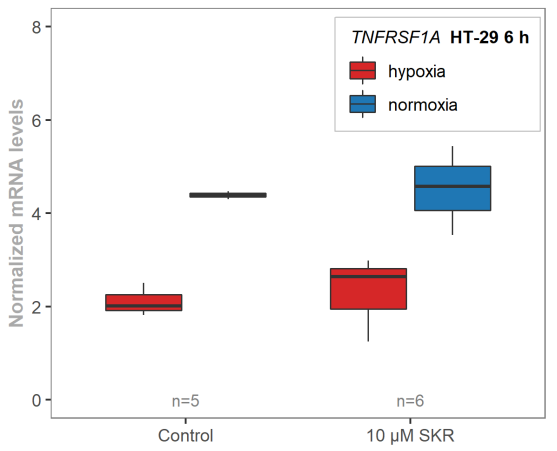

Figure 6. Normalized mRNA levels of TNFRSF10B (DR5), TNFRSF10A (DR4) and TNFRSF1A (TNFR1). Normalized mRNA levels of TNFRSF10B (DR5) of isoform $1(\mathbf{a}-\mathbf{c})$, isoform $2(\mathbf{d}-\mathbf{f})$ after SKR treatment. Normalized mRNA levels of TNFRSF10A (DR4) (g-i) and TNFRSF1A (TNFR1) (j-1). Normalized mRNA levels were evaluated by RT-qPCR and normalized to the level of reference gene $P M M 1$. The number of samples (n) is noted in plots. The experimental groups were compared with the matching control group $\left({ }^{*} p<0.05,{ }^{* * *} p<0.001\right)$. 
To complete the results from the analysis of the relevant proteins (detected by MS), an analysis of mRNAs encoding other TRAIL receptors and TNF-relevant proteins, namely DR4 (encoded by TNFRSF10A gene), TNF alpha (TNF), TNFR1 (TNFRSF1A), TNFR2 (TNFRSF1B) and DcR3 (TNFRSF6B), was performed. We found a significantly decreased mRNA level for DR4 (TNFRSF10A) in hypoxia after $48 \mathrm{~h}$ of SKR treatment in HCT 116 cell line (Figure 6g). In HT-29 cell line, no significant difference was observed (Figure 6h,i). The mRNAs of TNF as well as TNFR1 (TNFRSF1B) were below the limit of quantification in all samples. The amount of transcript encoding the TNF receptor TNFR2 (TNFRSF1A) was not significantly affected by SKR treatment within all analyzed samples (Figure 6j-1). Furthermore, the detected level of DcR3 mRNA was not influenced by the SKR treatment in both lines, although in HT-29 the mRNA level of the gene was below the limit of quantification.

\subsection{SKR Reverse TRAIL Resistance in p53 Mutated Cancer Cell Line Even in Hypoxia}

The next step was to determine whether the upregulation of DR5 was transformed to increase the sensitivity of cells to TRAIL. TRAIL solutions in concentrations based on our preliminary data were added to cells $24 \mathrm{~h}$ before the analysis ( $24 \mathrm{~h}$ after SKR treatment). The final concentration for HCT 116 cell line (TRAIL receptive cell line; p53 wild type) was $10 \mathrm{ng} / \mathrm{mL}$, and concentrations for HT-29 and SW620 cell lines (both are TRAIL-resistant cell lines; p53 R273H mutant cell lines) were $50 \mathrm{ng} / \mathrm{mL}$.

TRAIL increased the number of apoptotic cells in HCT 116 cell line in both conditions; however, the effect of TRAIL in hypoxia was less prominent than in normoxia. Conversely, effects of TRAIL only on HT-29 and SW620 cell lines were observed only in hypoxia. There was no significant effect of SKR with TRAIL on the induction of apoptosis in HCT 116 cell line in comparison with SKR alone (Figure 7i). On the other hand, SKR in combination with TRAIL decreased the number of live cells (Figure 7j). In HT-29 cell line as well as in SW620 cell line, the effect of TRAIL was amplified by SKR with a different level of effectiveness in both conditions, with a more prominent effect in hypoxia (Figures 8 and 9). Representative FACS plots are shown in Figure 7a-h, Figure 8a-h, Figure $9 a-h$, and primary FACS data with backgating are presented in the Supplementary Materials (Figures S6-S29). Therefore, we assume that SKR causes the upregulation of DR5 in TRAIL-receptive as well as TRAIL-resistant cell lines, leading to the sensitization of cells to the treatment targeting this receptor. 
a

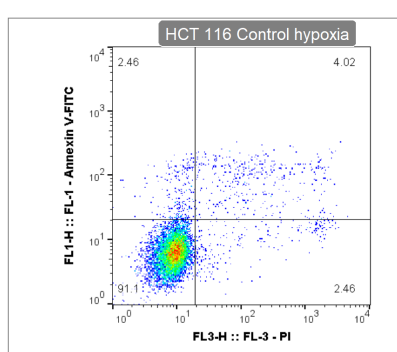

e

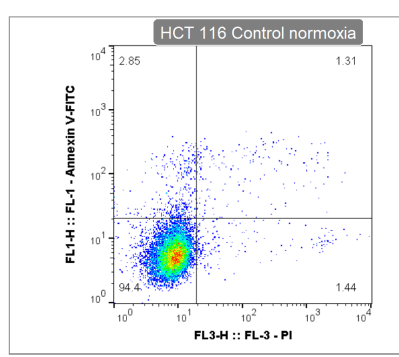

i

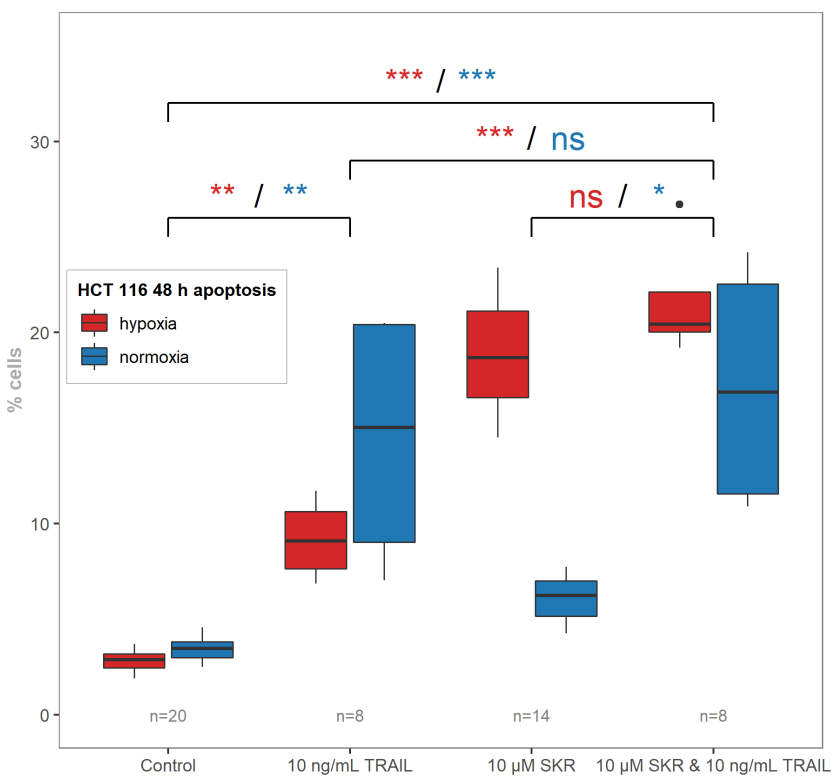

b

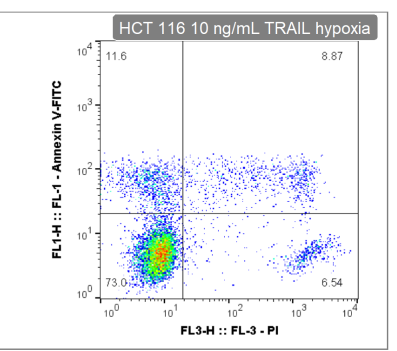

f

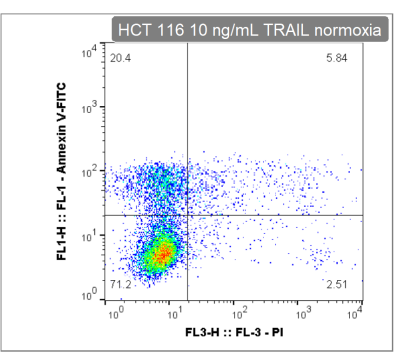

g

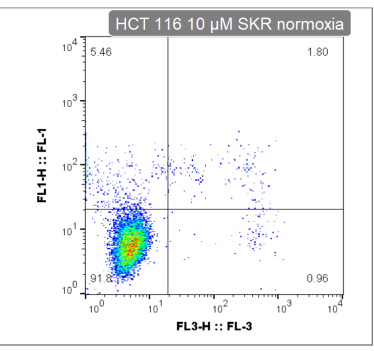

j

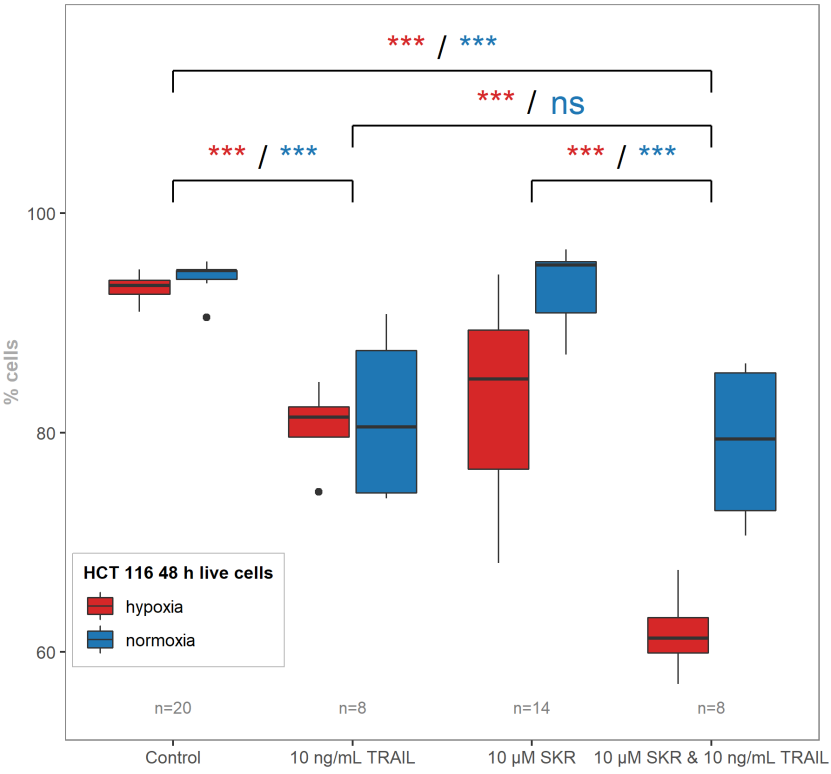

Figure 7. The effect of SKR in combination with TRAIL on the onset of apoptotic and live cells in HCT 116 cell line. (a-h) Representative FACS plots of debris-free singlets after SKR and TRAIL treatment in HCT 116 cell line. (i) Percentage of apoptotic cells after treatment with SKR and TRAIL after $48 \mathrm{~h}$ in HCT 116 cell line. (j) Percentage of live cells after treatment with SKR and TRAIL after $48 \mathrm{~h}$ in HCT 116 cell line. The experimental groups were compared with the matching control group or group, indicated with the line below marks. The color of the marks matches the cultivation conditions (hypoxia or normoxia). The number of samples (n) is noted in the plots. $\left({ }^{*} p<0.05,{ }^{* *} p<0.01,{ }^{* * *} p<0.001\right.$, ns-not significant) 
a

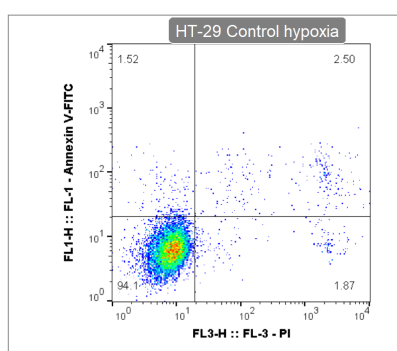

e

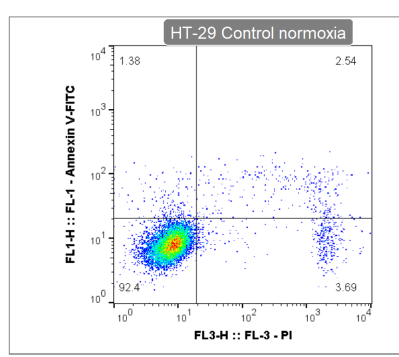

i

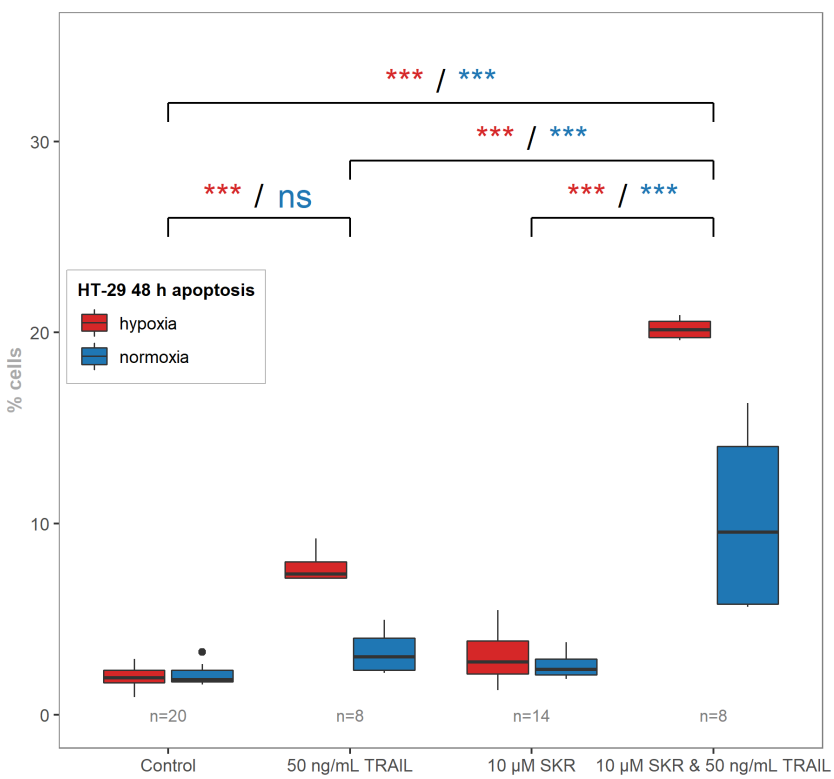

b

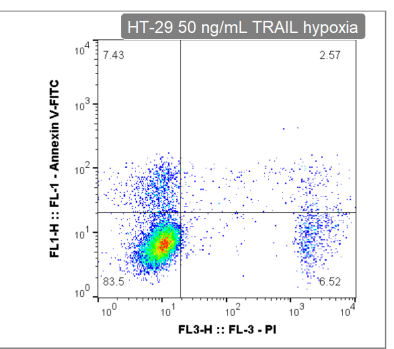

f

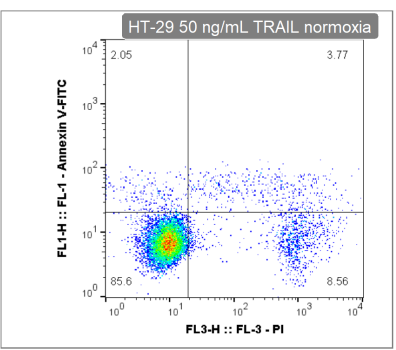

g
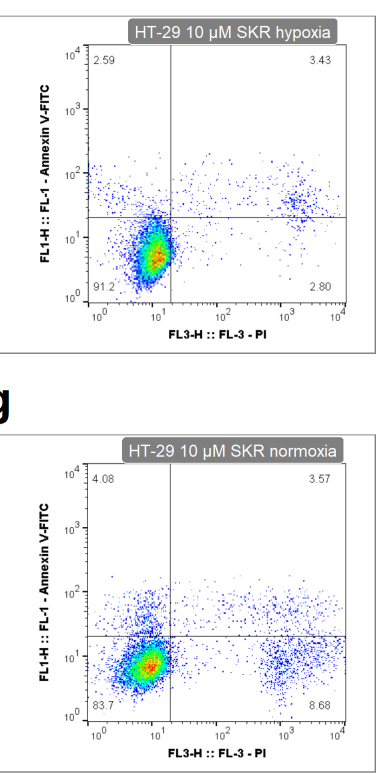

d

j

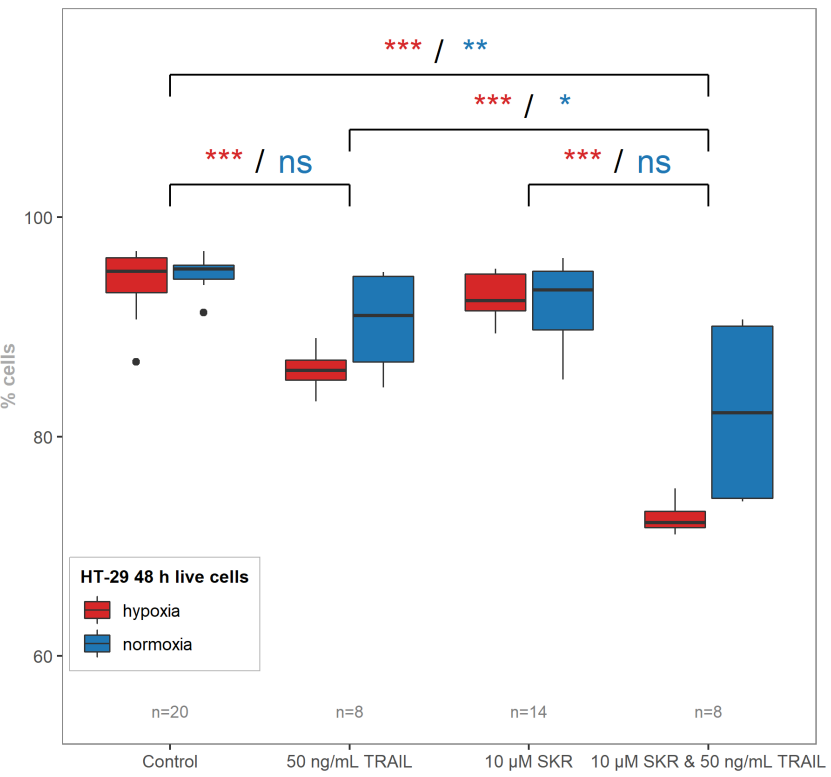

Figure 8. The effect of SKR in combination with TRAIL on the onset of apoptotic and live cells in HT-29 cell line. (a-h) Representative FACS plots of debris-free singlets after SKR and TRAIL treatment in HT-29 cell line. (i) Percentage of apoptotic cells after treatment with SKR and TRAIL after $48 \mathrm{~h}$ in HT-29 cell line. (j) Percentage of live cells after treatment with SKR and TRAIL after $48 \mathrm{~h}$ in HT-29 cell line. The experimental groups were compared with the matching control group or group, indicated with a line below marks. The color of the marks matches the cultivation conditions (hypoxia or normoxia). The number of samples (n) is noted in the plots. $\left({ }^{*} p<0.05,{ }^{* *} p<0.01,{ }^{* * *} p<0.001\right.$, ns-not significant) 
a

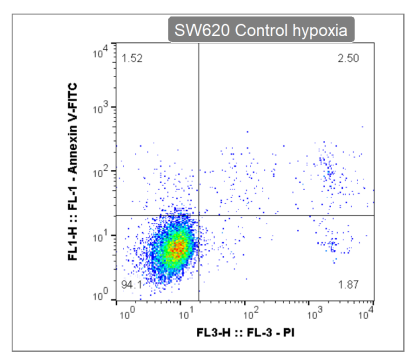

e

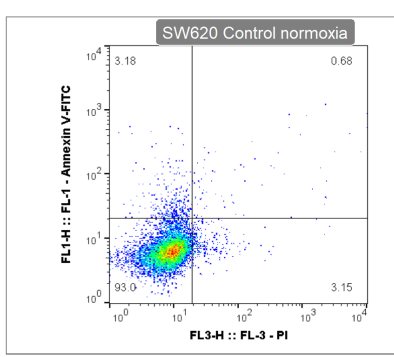

i

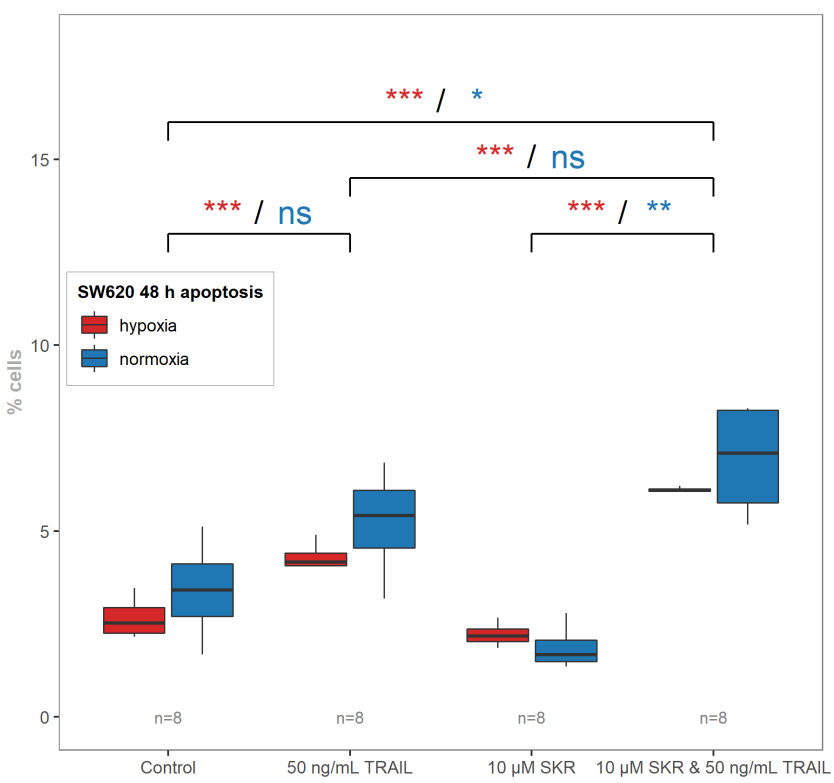

b

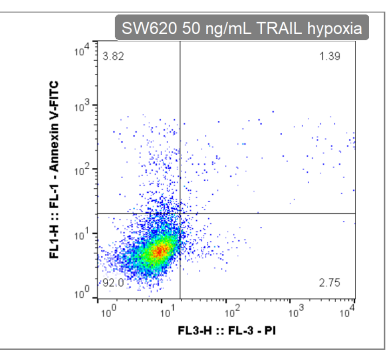

f

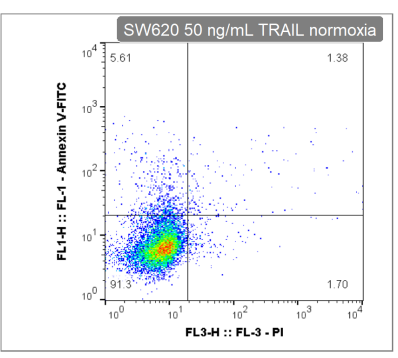

g

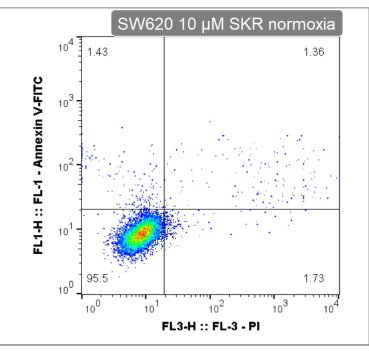

j

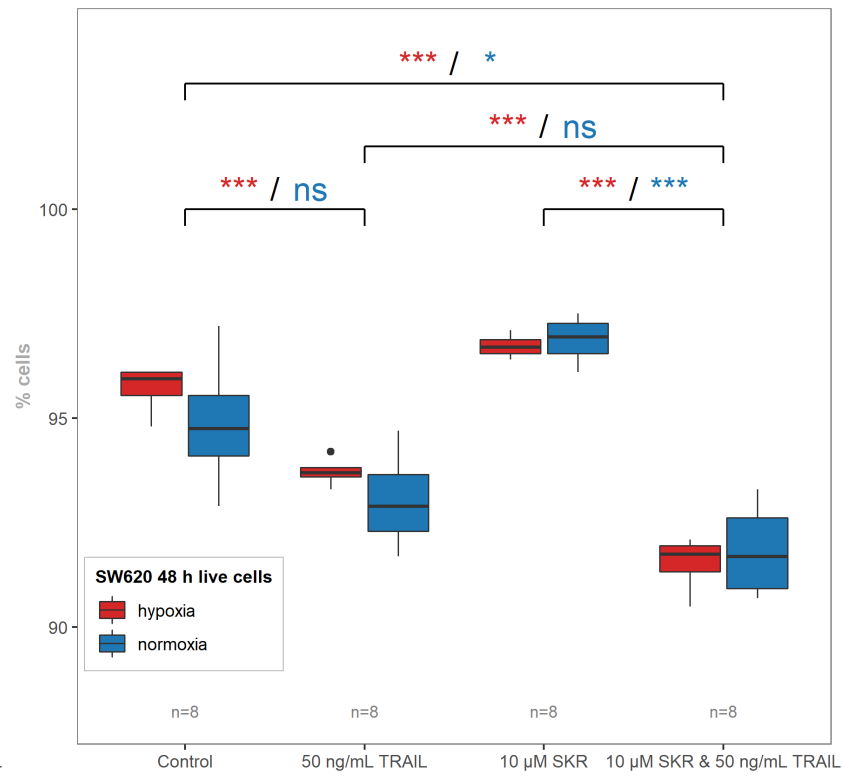

Figure 9. The effect of SKR in combination with TRAIL on the onset of apoptotic and live cells in SW620 cell line. (a-h) Representative FACS plots of debris-free singlets after SKR and TRAIL treatment in SW620 cell line. (i) Percentage of apoptotic cells after treatment with SKR and TRAIL after $48 \mathrm{~h}$ in SW620 cell line. (j) Percentage of live cells after treatment with SKR and TRAIL after $48 \mathrm{~h}$ in SW620 cell line. The experimental groups were compared with the matching control group or group, indicated with a line below marks. The color of the marks matches the cultivation conditions (hypoxia or normoxia). The number of samples (n) is noted in the plots. $\left({ }^{*} p<0.05,{ }^{* *} p<0.01,{ }^{* * *} p<0.001\right.$, ns-not significant)

\section{Discussion}

To determine the effect and the molecular background of the action of SKR, different cell lines cultivated under different cultivation conditions and exposed to different treatment regimens were used in our study. To do so, we analyzed the metabolic activity of SKR-treated cells, evaluated their cellularity, colony-forming ability, cell cycle distribution and the occurrence of apoptosis and necrosis and performed comparative proteomics analysis. 
In our study, two different human colorectal adenocarcinoma cell lines were used with distinct responses to SKR action and hypoxia. The main difference between these cell lines that could be manifested in their different sensitivity to SKR was that HCT 116 is a p53 wild-type cell line with defect DNA mismatch repair but without chromosomal instability [52]. In contrast, HT-29 is a p53 mutant with intact mismatch repair and chromosomal instability [52]. In our study, a more pronounced effect of SKR on HCT 116 cells was observed, which was reflected by decreased metabolic activity, an increased number of apoptotic cells and the accumulation of cells in G1. It is known that p53 knocked-out cells are more sensitive to treatment leading to DNA damage [53]. Moreover, HCT 116 cell line is more sensitive to apoptosis induced by 5-Fluorouracil and oxaliplatin because of the loss of Bax expression [54]. Based on these facts, we hypothesize that the observed effect of SKR probably does not depend on DNA damage.

The attenuated effect of SKR seen in HT-29 cell line can be associated with an overexpression of ATP-binding cassette super-family G member 2 (ABCG2) [55,56]. Elevated ABCG2 levels are responsible for decreasing the intracellular accumulation and thus the efficiency of another anthraquinone derivate-hypericin-as was shown by the decreased efficacy of the hypericin-mediated treatment of adenocarcinoma cells [56-58]. Many other anthraquinone derived drugs, such as mitoxantrone [59-62] or hypericin [56,57], are effluxed by ABCG2 transporter. Based on the chemical similarity of SKR to anthraquinone, we assume that SKR could be the substrate for ABCG2 transporter protein. This could explain the diminished impact of SKR on the metabolic activity of HT-29 cells (with overexpressed ABCG2) compared to HCT 116 cells (with low ABCG2 expression). Since SKR does not exhibit fluorescent properties, this needs to be further elucidated; e.g., using labeled SKR. Moreover, as our results show, HT-29 cells were not only more resistant to the effect of SKR but were also less impacted by hypoxia in general (when comparing HT-29 vs. HCT 116 but also untreated vs. treated HT-29). We assume that this could be mainly because HT-29 is more tolerant of the lack of oxygen than HCT 116 [52]. Nevertheless, the long-term cultivation in discontinued hypoxia leads to a more aggressive phenotype of HCT 116 cells [52]. Hypoxia induces several intracellular signaling pathways, such as hypoxia-inducible factor or PI3K/AKT/mTOR pathways [26].

Since we performed only an MS analysis of HCT 116 cells, we cannot confirm this assumption. However, based on a great deal of evidence from other studies, hypoxia potentiates both the level and activity of ABC transporter proteins, among which are ABCG2 and P-gp through the activation of ERK pathway $[34,63,64]$. Thus, the activity of efflux pumps should be significantly enhanced in hypoxia $[65,66]$. Despite that fact, a significant effect of SKR in hypoxia was noted in HCT 116, as well as in HT-29 with ABCG2 overexpression. Nevertheless, based on the literature, the upregulation of surface death receptors is associated with the inhibited efflux function of P-gp and downregulation of c-FLIP [67].

The dose-dependent negative effect of SKR on metabolic activity was proven in both used cancer cell lines. The effect of SKR on metabolic activity corresponds with the results of other authors. IC50 values of SKR in normoxic conditions vary from $20 \mu \mathrm{M}$ in L1210 cells [7] to $74 \mu \mathrm{M}$ in HL-60 cells [8] and $70 \mu \mathrm{M}$ in A549 cells [16]; thus, its effect is obviously highly dependent on cell type. The inhibition of the metabolic activity was observed in HeLa, Vero, K592, Raji, WISH, Calu-1 and HCT 116 cells. The IC50 of SKR for HCT 116 cells after $24 \mathrm{~h}$ presented in the literature was set to $59 \mu \mathrm{M}[11,16]$. For comparison, the concentration that decreases metabolic activity to $25 \%$ for HCT 116 cells in our study, based on an MTT assay, was set to $17.88 \pm 1.56 \mu \mathrm{M}$ in normoxia after $24 \mathrm{~h}$ and to $6.70 \pm 0.34 \mu \mathrm{M}$ in hypoxia after $48 \mathrm{~h}$ (Table 1 ). The theoretically calculated values for a $50 \%$ decrease of metabolic activity based on an MTT assay (only partially extrapolated from the linearized model calculated from observed data-the highest used concentration was $20 \mu \mathrm{M}$ ) are $33.27 \pm 3.17 \mu \mathrm{M}$ for $24 \mathrm{~h}$ in normoxia, $19.68 \pm 1.54 \mu \mathrm{M}$ for $48 \mathrm{~h}$ in normoxia, $38.03 \pm 4.09 \mu \mathrm{M}$ for $24 \mathrm{~h}$ in hypoxia and $14.84 \pm 0.55 \mu \mathrm{M}$ for $48 \mathrm{~h}$ in hypoxia. Moreover, we performed the analysis of the metabolic activity of pathologically unchanged cells in 
reaction to SKR treatment. We did not notice an inhibitory effect of SKR on healthy cells (Figure 1c), leading us to assume that SKR selectively affects cancer cells. Regarding the long-term effect of SKR on cell survival, similar to the attenuated colony-forming ability seen in MIA PaCa-2 cells in normoxia [16], we noticed a significantly decreased number of formed colonies in both cancer cell lines treated with SKR in hypoxia.

The level of apoptosis induced by SKR treatment can also be compared with the results of other authors. MIA PaCa-2 cells were treated with SKR in a concentration of $18 \mu \mathrm{M}$, and a significant increase of the number of apoptotic cells was observed by fluorescent microscopy via the detection of phosphatidylserine externalization with Annexin V [16]. In our study, the significant increase of apoptotic cells was observed in a $10 \mu \mathrm{M}$ concentration of SKR in HCT 116 cells (Figure 2). There were no changes in the number of apoptotic cells in HT-29 cell line after SKR treatment. The comparison of healthy cells without decreased metabolic activity and cancer cell lines with an increased apoptosis rate together with the upregulation of DR5 leads us to the assumption that the effect of SKR can be caused by the higher sensitivity of cells to TRAIL.

TRAIL also known as APOL2L (Apolipoprotein L2 ligand) or CD253, is a molecule that stimulates apoptosis in cancer cells but not in normal, nontransformed cells [36,37,68-72]. TRAIL is also an important immune effector agent regulating the growth of tumors [38]. However, the TRAIL resistance of tumor cells is a very common problem [70,72]. TRAIL resistance can be caused by a mutation in p53 [36] as well as the downregulation of DRs or upregulation of anti-apoptotic proteins [37]. A large number of drugs have been shown to overcome TRAIL resistance. The upregulation of its receptor, DR5, is the common way of sensitizing cells to treatment; for example, with doxorubicin [43,44], goniothalamin [73], emodin [45], ibuprofen [46], mitoxantrone [47], apigenin [74], Hsp90 inhibitors [75], resveratrol [76], indirubin-3-monoxime [77] or cyclopamine [78].

To verify the effect of SKR on TRAIL resistance, we also performed phosphatidylserine externalization analyses of samples with TRAIL treatment and a combination of SKR and TRAIL. HT-29 cell line is TRAIL-resistant, which correlates with a notably lower basal expression of DR5 as well as DR4 (Figure $6 \mathrm{~b}, \mathrm{c}, \mathrm{e}, \mathrm{f}, \mathrm{h}, \mathrm{i})$. In samples with TRAIL only, the effect in HT-29 was more pronounced in hypoxia, which was opposite to HCT 116 cell line, with a more prominent effect in normoxia. The effect of many TRAIL-targeted therapies is attenuated in hypoxia [74,78]. Furthermore, HCT 116 cells exposed to hypoxia are less susceptible to TRAIL than cells in normoxia, mainly because of the increase of antiapoptotic Bcl-2 [41,42] and because of the attenuated apoptosis signal due to mitochondria damage during oxygen deprivation [51]. However, TRAIL-induced apoptosis can bypass the intrinsic apoptosis pathway controlled by Bcl-2 in cancer [79].

TRAIL in combination with SKR has a cooperative effect in hypoxia on HCT 116 cell line based on the decreased number of live cells (Figure 7j). In normoxia, the effect of SKR and TRAIL was on the level of TRAIL. We assume that the lack of an increase of apoptotic cells can be caused by the relative overabundance of DR5, as well as in HCT 116 cells without SKR pretreatment, where the amount of naturally present TRAIL in the medium is sufficient for apoptosis to be switched on.

There was also an enhanced effect of TRAIL on apoptosis induction in SKR-pretreated cells in HT-29 cell line in hypoxia as well in normoxia (Figure 8). In SW620 cell line, the only noted effect was that the hypoxia-based TRAIL resistance was reversed; in normoxia, only a non-significant increase was observed (Figure 9). In both resistant cancer cell lines, the upregulation of DR5 was reported. In HT-29, there was a significant increase in both isoforms of TNFRSF10B with different mRNA level kinetics. After $6 \mathrm{~h}$, the upregulation was observed in hypoxia, without a change in normoxia, as in the SW620 cell line. In normoxia, the upregulation of DR5 on the mRNA level was observed in HT-29 in both isoforms after $48 \mathrm{~h}$ but without the changes in normoxia. The upregulation of death receptors (DR4 or DR5) induces apoptosis $[73,80]$. On the other hand, we assume that the lack of an effect of a single SKR treatment on the apoptosis of HT-29 and SW620 can be caused by an insufficient 
amount of naturally present TRAIL ligand [81] in cultivation media for the induction of apoptosis; i.e., an amount below the apoptosis-inducing threshold.

In TRAIL-resistant cancer cell lines (HT-29 and SW620), the effect of SKR and TRAIL in combination was significantly cooperative. The upregulation of the receptor can be connected to the higher sensitivity of the cell to the ligand; in this case, TRAIL, which results in the induction of apoptosis through caspase- 8 activity and Bid cleavage [82]. We also confirmed the upregulated levels of TNFRSF10B mRNA in all cell lines after SKR treatment.

To complete the overall view of the effect of SKR on cells, the RT-qPCR analysis of other TNF-related genes was performed. TNF (TNF alpha) as well as TNFRSF1B (TNFR2) were below the limit of quantification, which corresponded with the available data from the databases. The absence of significant changes in normalized mRNA levels of TNFRSF1A (TNFR1) and TNFRSF6B (DcR3) leads us to the assumption that the effect of SKR is not mediated by TNF alpha.

For a confirmation of TRAIL pathway activation in cells after treatment with SKR, we compared the expected proteomic changes with observed changes acquired from the quantitative mass spectrometry data. According to the literature, the TRAIL signaling pathway is triggered by the binding of a ligand to DR5 and results in a cascade of reactions. For example, the nuclear factor kappa B (NF- $\kappa$ B) pathway is downregulated, which is connected to the decrease of cell survival and activation of genes involved in immune reaction and inflammation. The key regulatory protein of this cascade is NF- $\kappa$ B essential modulator (NEMO), which is upregulated as a result of TRAIL pathway activation [83,84]. In our study, NEMO, the regulatory subunit of the inhibitor I $\kappa$ B kinase complex, which activates the NF- $\kappa$ B pathway, was significantly upregulated after the treatment with SKR in hypoxia $(\log 2 \mathrm{FC}=1.45)$. In normoxia, we observed only a nonsignificant increase of NEMO. The difference between hypoxia and normoxia can be also demonstrated by the comparison of control samples, where NEMO is significantly downregulated in hypoxia compared to normoxia. Additionally, the inhibition of the PI3K pathway sensitized tumor cells to TRAIL treatment [85]. The deactivation of PI3K leads to the deactivation of mTOR and further deregulation of p70 protein. In our study, the p70 was not significantly reduced after the treatment with SKR. Moreover, the BIRC6 protein, known as Livin, was downregulated in hypoxia $(\log 2 \mathrm{FC}=-0.94)$ as well as normoxia $(\log 2 \mathrm{FC}=-0.43)$. The downregulation of BIRC6 is related to TRAIL pathway activation [86]. Likewise, NEDD4 regulates the tumor-suppressor PTEN by ubiquitin-mediated proteasomal degradation $[70,87,88]$. Thus, the downregulation of NEDD4 by SKR in hypoxia and normoxia $(\log 2 \mathrm{FC}=-3.70$ and -3.94) could be responsible for decreased PTEN degradation, leading to the impedence of cell growth and migration and promotion of apoptosis. TRAIL signalization in hypoxia partially leads to necrosis at the expense of apoptosis. This mechanism is controlled by low extracellular $\mathrm{pH}$ [89]. The key proteins are RIPK1 and PARP-1. Their inhibition is connected to decreased necrosis due to the switched TRAIL pathway $[84,89,90]$. In our samples, there was no change in the regulation of RIPK1 in normoxia after SKR treatment; in hypoxia alone, this protein was not significantly upregulated.

The analysis of the metabolic activity, cellularity and colony-forming ability of cells after SKR treatment was used to determine the overall effect of SKR on cells. HCT 116 cell line, which expresses only a low level of the potential SKR transporter ABCG2 and is less tolerant to hypoxia, showed higher sensitivity to SKR treatment. This was demonstrated by a decreased metabolic activity, cellularity and accumulation of cells in the G1 phase. We did not observe the effect of SKR on healthy cells. Moreover, the increased number of apoptotic cells after treatment with SKR in HCT 116 cell line correlated with the observations from MS. These data indicate that the potential mechanism of SKR action can be mediated by the upregulation of DR5. This was also confirmed by RTq-PCR and changes in downstream of TRAIL-activated cascade after DR5 stimulation. SKR also reverses TRAIL resistance in HT-29 cell line in hypoxia and normoxia as well as eliminating the lack of an effect of TRAIL to HCT 116 and SW620 cells in hypoxia. 


\section{Materials and Methods}

\subsection{Reagents}

SKR (CAS no: 602-06-2, Sigma-Aldrich, St. Louis, MO, USA) stock solution (c = $5 \mathrm{mM}$ ) was prepared in dimethylsulfoxide (DMSO) and further diluted to freshly prepared working solutions immediately before addition to cell cultures. In experiments, the control sample with the same concentration of DMSO as the sample with $10 \mu \mathrm{M}$ was used to establish the effect of the carrier. Recombinant TRAIL protein (Abcam, Cambridge, UK; ab9960) stock solution $(0.5 \mathrm{mg} / \mathrm{mL})$ was prepared by the reconstitution of lyophilized powder in pure water and further diluted to freshly prepared working solutions immediately before use.

\subsection{Cell Cultures}

HT-29, HCT 116, SW620, CCD-18Co and CCD-1072Sk cell cultures were purchased from American Type Culture Collection (ATCC, Rockville, MD, USA). HT-29 and SW620 cells were cultured in complete RPMI-1640 medium (Sigma-Aldrich, St. Louis, MO, USA), HCT 116 cells in McCoy's medium (PAN-Biotech GmbH, Aidenbach, Germany), CCD18Co and CCD-1072Sk in MEM medium (Biosera, Nuaille, France). All cultivation media were supplemented with 10\% fetal bovine serum (Biosera, Nuaille, France) and antibiotics ( $1 \%$ antibiotic-antimycotic $100 \times$ and $50 \mu \mathrm{g} / \mathrm{mL}$ gentamicin; Biosera, Nuaille, France).

\subsection{Cultivation Conditions and Experimental Design}

To compare the effect of SKR on cancer cells under different oxygen concentrations, cells were cultivated in a glove box under controlled conditions (Coy Laboratory Products, Inc., Grass Lake, MI, USA) with two separate cabinets. The oxygen concentration in the hypoxic cabinet was set to $1 \%$ (partially $1 \%$ of $\mathrm{O}_{2}, 5 \%$ of $\mathrm{CO}_{2}, 94 \%$ of $\mathrm{N}_{2}$ ) and in the normoxic cabinet to $20 \%$ (partially $20 \%$ of $\mathrm{O}_{2}, 5 \%$ of $\mathrm{CO}_{2}, 75 \%$ of $\mathrm{N}_{2}$ ). Humidity and temperature were the same for both cabinets; i.e., $95 \%$ and $37{ }^{\circ} \mathrm{C}$, respectively.

After seeding, cells were allowed to settle for $8 \mathrm{~h}$ at standard conditions in an incubator. Subsequently, cells were moved to hypoxic or normoxic chambers and cultivated for $16 \mathrm{~h}$. Then, SKR solutions (from $0.5 \mu \mathrm{M}$ to $20 \mu \mathrm{M}$ ) were added to cells for 24 or $48 \mathrm{~h}$ with subsequent analysis. All experiments (except the mass spectrometry analysis, RT-qPCR analysis and phosphatidylserine externalization analysis in combination with TRAIL) were performed at least in three independent technical and biological replicates for all measured factors: (1) cell lines: HT-29 and HCT 116; (2) oxygen content: $1 \%$ and 20\%; and (3) time of cultivation: 24 and $48 \mathrm{~h}$.

\subsection{Metabolic Activity Assay}

Metabolic activity assays (MTT) were performed as reported previously [49] to evaluate changes in the metabolic activity of cells after treatment with SKR. Solutions of SKR (from $0.5 \mu \mathrm{M}$ to $20 \mu \mathrm{M}$ ) were added to cells in a 96-well plate (TPP Techno Plastic Products AG, Trasadingen, Switzerland) to examine the SKR effect on metabolic activity based on MTT assay and to determine SKR concentrations for further experiments. Of note, IC50 values can be only extrapolated, because of the relatively low inhibition rate of SKR after the shorter incubation period. After 24 and $48 \mathrm{~h}$, MTT (3-[4,5-dimethylthiazol-2-yl]-2,5diphenyltetrazolium bromide) (Sigma-Aldrich, St. Louis, MO, USA) from a stock solution $(5 \mathrm{mg} / \mathrm{mL})$ was added to the cells in a 96-well plate. The reaction was stopped after $4 \mathrm{~h}$ incubation and the insoluble formazan was dissolved by the addition of SDS at a final concentration of $3.3 \%$. The absorbance of metabolized formazan $(\lambda=584 \mathrm{~nm})$ was measured using a BMG FLUOstar Optima (BMG Labtech GmbH, Offenburg, Germany). Results were evaluated as the ratio of the absorbance of the treated sample to the untreated matching control. The experimental groups were compared with the matching control groups (normoxic control or hypoxic control). 


\subsection{Analysis of Cellularity and Cell Size}

The analysis of cellularity (the total number of cells in the sample) and cell size was performed using the Vi-CELL XR Cell Viability Analyzer (Beckman Coulter, Indianapolis, IN, USA). Floating and adherent cells were harvested for analysis by trypsinization at scheduled time points, washed with PBS and analyzed. Cellularity is presented as the ratio of total cell numbers to the average total number of cells from all samples of the experiment. Cell size was evaluated automatically as the average diameter of cells in $\mu \mathrm{m}$ in the analyzed cell suspension. The experimental groups were compared with the matching control groups (normoxic control or hypoxic control).

\subsection{Phosphatidylserine Externalization Analysis}

For the measurement of the viability and phosphatidylserine externalization as a marker of apoptosis, a BD Pharmingen FITC Annexin V Apoptosis Detection Kit I (BD Biosciences, San Jose, CA, USA) was used according to the manufacturer's instructions. Total cells were harvested 24 and $48 \mathrm{~h}$ after SKR addition. Cells were washed with PBS, centrifuged and stained with Annexin V-FITC for $20 \mathrm{~min}$ at room temperature in the dark and subsequently stained with propidium iodide (PI) for $5 \mathrm{~min}$ before the measurement. A total number of 10,000 cells per sample were analyzed using a BD FACSCalibur flow cytometer (BD Biosciences, San Jose, CA, USA). Fluorescence was detected via a 530/30 nm band-pass filter (FL-1; Annexin V-FITC) and a $670 \mathrm{~nm}$ long-pass filter (FL-3; PI). Raw files were analyzed using FlowJo software (Tree Star Inc., Ashland, OR, USA). Only debris-free single cells were analyzed. Examples of gating strategies are presented in the Supplementary Materials (Figures S6-S29). An apoptotic cell was considered as Annexin $\mathrm{V}^{+} / \mathrm{PI}^{-}$, a secondary necrotic cell was Annexin $\mathrm{V}^{+} / \mathrm{PI}^{+}$, a necrotic cell was an Annexin $\mathrm{V}^{-} / \mathrm{PI}^{+}$cell and a live cell was Annexin $\mathrm{V}^{-} / \mathrm{PI}^{-}$. Results are presented as the average percentage of cells from three independent experiments. The experimental groups were compared with the matching control groups (normoxic control or hypoxic control) or with other samples.

\subsection{Analysis of Cell Cycle Distribution}

To analyze the effect of SKR on the whole population of cells, the cell cycle distribution of cells was examined. Adherent cells were harvested by trypsinization and together with floating cells were washed with cold PBS, centrifuged, fixed in cold $70 \%$ ethanol and stored at $-20{ }^{\circ} \mathrm{C}$ (at least overnight) for further analysis. Fixed cells were subsequently centrifuged, washed with PBS, and stained with staining solution $(20 \mu \mathrm{g} / \mathrm{mL}$ PI, $137 \mu \mathrm{g} / \mathrm{mL}$ RNAse A and $0.1 \%$ Triton X-100 in PBS). After 30 min incubation in the dark, samples were measured with BD FACSCalibur flow cytometer (BD Biosciences, San Jose, CA, USA). To analyze the raw files, ModFit 3.0 (Verity Software House, Topsham, ME, USA) was used. Only debris-free single cells were analyzed. Examples of gating strategies are presented in the Supplementary Materials (Figures S30-S37). The results are presented as the average ratio of cells in the individual phase to all cells from three independent experiments. The experimental groups were compared with the matching control groups (normoxic control or hypoxic control).

\subsection{Colony Forming Assay}

For the analysis of the colony-forming ability, HCT 116 and HT-29 cells from hypoxia and normoxia were harvested by trypsinization, washed with PBS, centrifuged and resuspended in PBS. Then, cells were counted using Vi-CELL XR Cell Viability Analyzer (Beckman Coulter, Indianapolis, IN, USA) and seeded as 500 cells per well in fresh medium in a six-well plate (TPP Techno Plastic Products AG, Trasadingen, Switzerland). After 8 days of incubation, the medium was removed and formed colonies were washed with PBS and stained with methylene blue dye in methanol (0.8\%). Afterwards, the dye was removed and the colonies were washed with PBS and subsequently scanned. All independent experiments were performed in technical duplicate (two wells from each sample) in 
three independent experiments. Colonies were counted using ImageJ (version 1.8.0; NIH, Bethesda, MA, USA) using the Colony Counter plugin (version 0.9), manually checked and corrected as needed. The results are presented as the number of colonies. Values are presented as technical duplicates from biological triplicates for each sample. To avoid the effect of the solvent, the control sample contained the same amount of DMSO as a sample with a higher concentration of SKR. The experimental groups were compared with the matching control groups (normoxic control or hypoxic control).

\subsection{Mass Spectrometry}

Mass spectrometry analysis (MS) was performed in the Proteomic Core Facility of Central European Institute of Technology (CEITEC), Brno, Czech Republic. Based on our previous results, HCT 116 cell line treated with SKR $(10 \mu \mathrm{M})$ for $48 \mathrm{~h}$ in normoxia or hypoxia and a matching control were chosen for this analysis. Biological triplicates of all samples were prepared.

\subsubsection{Sample Preparation}

Samples were washed three times with ice-cold PBS to prevent the contamination of samples with serum proteins in cultivation media. Then, cells were harvested by scraping in ice-cold PBS and subsequently centrifuged. Pellets were resuspended in $50 \mu \mathrm{L}$ of SDT lysis buffer (4\% sodium dodecyl sulfate (SDS), $0.1 \%$ dithiothreitol (DTT) in Tris $/ \mathrm{HCl} \mathrm{pH}$ 7.6) and homogenized for $120 \mathrm{~min}$ at $95{ }^{\circ} \mathrm{C}$ on aThermoMixer (Eppendorf, Hamburg, Germany). After perfect homogenization, samples were stored at $-80^{\circ} \mathrm{C}$. Samples for LC-MS analyses were prepared using filter-assisted sample preparation (FASP; Merck Millipore, Burlington, MA, USA) from $5 \mu \mathrm{L}$ of the protein mixture. Protein reduction and alkylation with iodoacetamide and $30 \mathrm{kDa}$ cut-off filters were used. Samples were incubated for $18 \mathrm{~h}$ with trypsin at $37^{\circ} \mathrm{C}$, and resulting peptides were extracted into $15 \mu \mathrm{L}$ of the final solution.

\subsubsection{MS Measurement and Analysis}

Mass spectrometry analysis of the peptide mixture was done using the RSLCnano system, which was connected online to an Orbitrap Q-Exactive HF-X system (Thermo Fisher Scientific, Waltham, MA, USA). Prior to LC separation, tryptic digests were concentrated and desalted online using a cartridge trapping column $(300 \mu \mathrm{m} \times 5 \mathrm{~mm})$ filled with $5 \mu \mathrm{m}$ particles C18 PepMap100 sorbent (Thermo Fisher Scientific, Waltham, MA, USA). The peptides were eluted from the trapping column onto an Acclaim Pepmap100 C18 analytical column (3- $\mu \mathrm{m}$ particles, $75 \mu \mathrm{m} \times 500 \mathrm{~mm}$; Thermo Fisher Scientific, Waltham, MA, USA) and separated by the following gradient program: mobile phase A: $0.1 \%$ formic acid in 5\% DMSO water; mobile phase B: $0.1 \%$ formic acid and 5\% DMSO in $80 \%$ acetonitrile, flow rate $300 \mathrm{~nL} / \mathrm{min}$. The gradient elution started at $2 \%(0-5$ th $\mathrm{min}$ ) of mobile phase $\mathrm{B}$, increased from $2 \%$ to $35 \%$ (5th-105th min), then increased linearly to $90 \%$ (105th-110th min) of mobile phase $B$ and remained at this state for the next $10 \mathrm{~min}$. The equilibration of the trapping column and the column was done prior to sample injection to the sample loop. For quality control purposes, Biognosys iRT peptides (Biognosys AG, Schlieren, Switzerland) were added during each analysis. The samples were measured in a random order with a blank analysis for the samples. Approximately $2000 \mathrm{ng}$ was subjected to LC-MS analysis per sample. The analytical column outlet was directly linked to the Digital PicoView 550 (New Objective, Woburn, MA, USA) ion source with sheath gas option and SilicaTip emitter (FS360-20-15-N-20-C12; New Objective, Woburn, MA, USA) utilization. An ABIRD (Active Background Ion Reduction Device; ESI Source Solutions, Woburn, MA, USA) was installed. MS data were acquired in a data-dependent strategy, selecting up to the top 20 precursors based on precursor abundance in the survey scan (350-2000 m/z). The resolution of the survey scan was $120,000($ at $200 \mathrm{~m} / \mathrm{z})$ with a target value of $3 \times 10^{6}$ ions and a maximum injection time of $100 \mathrm{~ms}$. HCD MS/MS spectra were acquired with a target value of $1 \times 10^{5}$ and resolution of 15,000 (at $200 \mathrm{~m} / \mathrm{z}$ ). The maximum injection 
time for MS/MS was $50 \mathrm{~ms}$. Dynamic exclusion was enabled for $40 \mathrm{~s}$ after one MS/MS spectrum acquisition. The isolation window for MS/MS fragmentation was set to $1.2 \mathrm{~m} / \mathrm{z}$.

LC-MS data processing was done using MaxQuant software (version 1.6.2.10; Max Planck Institute of Biochemistry, Martinsried, Germany) with Andromeda search engine [91,92]. UniProtKB database (taxonomy: human; taxon ID: 9606; version 180912) and MaxQuant contaminant database of 247 protein sequences were used. Matches between runs were used across biological replicates datasets to improve peptide matching. Results were set to follow a $1 \%$ false discovery rate of peptide-to-spectrum matches and protein levels. The minimal number of unique and razor peptides was set to 1 . The mass spectrometry proteomics data have been deposited to the ProteomeXchange Consortium via the PRIDE partner repository with the dataset identifier PXD019995. Intensities of identified proteins were normalized across all samples prior to further data evaluation. Several normalization approaches were tested and the LoessF normalization was finally selected. Log2 intensities were calculated and used for further analysis. In addition, Pearson's pairwise correlation coefficients were calculated, using data for all protein groups with a non-zero protein group area for the given pair of samples for sample cluster analysis. Comparative proteomics was performed by the LIMMA test and the Benjamini Hochberg method. Fold change (FC) and Log2FC values were also calculated and exported as CSV data. This analysis was performed in the KNIME analytics platform (KNIME AG, Zurich, Switzerland) using the KNIME proteomic workflow created by the CEITEC MU Proteomics laboratory (available under GPL-3.0 license at https:/ / github.com/OmicsWorkflows, accessed on 27 August 2019). For the final report, the following parameters were set as follows: changed proteins needed to have a Log2FC higher than 1.0 or lower than -1.0 between treated samples to control samples and to be significantly changed simultaneously in both conditions (hypoxia and normoxia).

\subsection{RT-qPCR Analysis}

The normalized relative mRNA levels of all analyzed genes (Table 5) were quantified by real-time RT-qPCR with SYBR Green I detection of the amplicons. The levels of the studied genes were normalized with the reference gene PMM1 (Gene ID: 5372). The cDNA template for RT-qPCR was prepared from total RNA by RevertAid-MuLV Reverse Transcriptase (RevertAid First Strand cDNA Synthesis Kit, Thermo Fisher Scientific Inc., Waltham, MA, USA) and a random primer mix (a mixture of anchored-dT and random hexamer primers; NEB, Ipswich, MA, USA). Total RNA was isolated by TRI Reagent (MRC Inc, Cincinnati, OH, USA) according to the manufacturer's instructions. RNA integrity was verified by agarose gel electrophoresis and the amount of $\mathrm{RNA} / \mu \mathrm{L}$ was determined using a BioSpec nano-spectrophotometer (Shimadzu, Kyoto, Japan). Only samples with distinct 28S/18S RNA bands were used for cDNA transcription. Human-specific primers for the respective genes were designed by PrimerBLAST [93] hosted at the NCBI web page. The primers either spanned two neighboring exons or were bound to different exons. Primer pairs with no secondary structures and the best delta $G$ values were chosen by Unipro UGENE v1.20.0 software [94].

Table 5. Sequences of used RT-qPCR primers. Annealing Temperatures (Ta) and Product Lenghts are in table.

\begin{tabular}{lllll}
\hline Gene (NCBI Gene ID) & $\begin{array}{l}\text { GenBank } \\
\text { Ref.seq }\end{array}$ & Primer Name & Sequence & $\begin{array}{l}\text { Ta and Product } \\
\text { Length }\end{array}$ \\
\hline TNFRSF10B & NM_003842 & DR5_for & GTGATTCAGGTGAAGTGGAGC & $60{ }^{\circ} \mathrm{C}$ \\
\cline { 3 - 4 }$(8795)$ & NM_147187 & DR5_rev & CGACCTTGACCATCCCTCTG & 147 bp \\
\hline TNFRSF10B & NM_003842 & DR5.v1_for & ACTCCTGCCTCTCCCTGTTC & $60{ }^{\circ} \mathrm{C}$ \\
\cline { 3 - 4 }$(8795)$ & & DR5.v1_rev & AGGTCGTTGTGAGCTTCTGTC & 186 bp \\
\hline
\end{tabular}


Table 5. Cont.

\begin{tabular}{|c|c|c|c|c|}
\hline Gene (NCBI Gene ID) & $\begin{array}{l}\text { GenBank } \\
\text { Ref.seq }\end{array}$ & Primer Name & Sequence & $\begin{array}{l}\text { Ta and Product } \\
\text { Length }\end{array}$ \\
\hline \multirow{2}{*}{$\begin{array}{l}\text { TNFRSF10B } \\
\text { (8795) }\end{array}$} & \multirow{2}{*}{ NM_147187 } & DR5.v2_for & CTAAGTCCCTGCACCACGAC & $60^{\circ} \mathrm{C}$ \\
\hline & & DR5.v2_rev & TGACTCCTATGATGATGCCTGATT & $193 \mathrm{bp}$ \\
\hline \multirow{2}{*}{$\begin{array}{l}\text { TNFRSF10A } \\
(8797)\end{array}$} & \multirow{2}{*}{ NM_003844 } & DR4_for & GTTGGTGGCTGTGCTGATTG & $60{ }^{\circ} \mathrm{C}$ \\
\hline & & DR4_rev & TGCGTTGCTCAGAATCTCGT & $151 \mathrm{bp}$ \\
\hline \multirow{2}{*}{$\begin{array}{l}\text { TNF (TNF alpha) } \\
\text { (7124) }\end{array}$} & \multirow{2}{*}{ NM_000594 } & TNFa_for & TGTCCACACGATCCCAACAC & $60^{\circ} \mathrm{C}$ \\
\hline & & TNFa_rev & GGCTGTCACACCCACAATCA & $152 \mathrm{bp}$ \\
\hline \multirow{2}{*}{$\begin{array}{l}\text { TNFRSF1A } \\
(7132)\end{array}$} & \multirow{2}{*}{ NM_001065 } & TNFRSF1A_for & CGTGATCTCTATGCCCGAGT & $60{ }^{\circ} \mathrm{C}$ \\
\hline & & TNFRSF1A_rev & GACCAGTCCAATAACCCCTGA & $244 \mathrm{bp}$ \\
\hline \multirow{2}{*}{$\begin{array}{l}\text { TNFRSF1B } \\
(7133)\end{array}$} & \multirow{2}{*}{ NM_001066 } & TNFRSF1B_for & TGTCCACACGATCCCAACAC & $60{ }^{\circ} \mathrm{C}$ \\
\hline & & TNFRSF1B_rev & GGCTGTCACACCCACAATCA & $152 \mathrm{bp}$ \\
\hline \multirow{2}{*}{$\begin{array}{l}\text { TNFRSF6B } \\
(8771)\end{array}$} & \multirow{2}{*}{ NM_003823 } & DcR3_for & СТСТTССТСССАТGАСАСССТ & $60^{\circ} \mathrm{C}$ \\
\hline & & DcR3_rev & ATGGAGATGTCCTGGAAAGCC & $123 \mathrm{bp}$ \\
\hline \multirow{2}{*}{$\begin{array}{l}\text { PMM1 } \\
(5372)\end{array}$} & \multirow{2}{*}{ NM_002676 } & PMM1_for & GCTCGCCAGAAAATTGACCCT & $61{ }^{\circ} \mathrm{C}$ \\
\hline & & PMM1_rev & ATACTGCACCGTCCCGTTCT & $177 \mathrm{bp}$ \\
\hline
\end{tabular}

RT-qPCR experiments were performed using a CFX96 Touch Real-Time PCR Detection System (BioRad Laboratories, Hercules, CA, USA). For amplification reactions, Xceed qPCR SG Mix, Lo-Rox (IAB, Prague, Czech Republic), $0.5 \mu \mathrm{M}$ For/Rev primers and $15 \mathrm{ng}$ of RNA/cDNA were used. The conditions for RT-qPCR were according to Majernik et al. [49]. The amplification of single and specific gene fragments in the RT-qPCR was confirmed by melt curve analysis and by checking the size of the amplicon by agarose gel electrophoresis. The melt curves for all used primer pairs used are shown in the Supplementary Materials (Figures S38-S46). All samples were analyzed in biological triplicates from independently repeated experiments. The resulting values of target mRNA levels were normalized to the levels of $P M M 1$, which was shown to be an accurate internal reference control in HCT 116, HT-29 and SW620 cell lines. The results are presented as the PMM1-normalized mRNA level. The experimental groups were compared with the matching control groups (normoxic control or hypoxic control).

\subsection{Statistical Analysis}

Data were analyzed and visualized using in the R environment [95] (version 4.0.3) using the standard library and libraries noted listed in Table S1 in the Supplementary Materials [95-108]. Significance between samples was assessed by a one-way ANOVA with Tukey's post-test. Significance levels are presented as follows: ${ }^{*} p<0.05,{ }^{* *} p<0.01$, ${ }_{* * *} p<0.001$. For comparative proteomics, the LIMMA test and the Benjamini Hochberg method was performed. Significance levels are indicated in the capture for each figure.

\section{Conclusions}

In this article, we present a comprehensive analysis of the effect of the natural secondary metabolite SKR on cancer cells. We described the SKR-induced changes on many different levels, from the overall influence on the cellularity and metabolic activity of cells through the effects on whole cell populations to mass spectrometry analysis on the molecular level. Many biomolecules are currently used in cancer treatment, and we demonstrated 
that SKR possesses comparable features with other drugs. SKR has a significantly negative effect on cancer cells, induces apoptosis, upregulates DR5 in normoxic as well as hypoxic conditions without an effect on pathologically unchanged healthy cells and reverses TRAIL resistance in hypoxia as well as in TRAIL-resistant cell lines. Our results indicate the possible usage of SKR as an antitumor drug or as an adjuvant to other established treatments by increasing the accumulation of structurally similar molecules or by the sensitization of cells to TRAIL-targeted treatment.

Supplementary Materials: The supplementary materials are available online https:/ /www.mdpi. com/article/10.3390/cancers13071646/s1, Data S1: List of all identified protein groups, Table S1: Used R libraries, Figure S1: The effect of SKR on average diameter of cells, Figure S2: The effect of SKR on cellularity, Figure S3: The effect of SKR on proportions of cells in apoptosis, secondary necrosis, necrosis and live cells, Figure S4: The effect of SKR on cell cycle distribution, Figure S5: Normalized mRNA levels of TNFRSF10B in different cell lines in different times, Figure S6: Phosphatidylserine externalization analysis gating strategy example (HCT 116, hypoxia, Control, $48 \mathrm{~h}$ ), Figure S7: Phosphatidylserine externalization analysis gating strategy example (HCT 116, hypoxia, $10 \mathrm{ng} / \mathrm{mL}$ TRAIL, $48 \mathrm{~h}$ ), Figure S8: Phosphatidylserine externalization analysis gating strategy example (HCT 116, hypoxia, $10 \mu \mathrm{M} \mathrm{SKR}, 48$ h), Figure S9: Phosphatidylserine externalization analysis gating strategy example (HCT 116, hypoxia, $10 \mu \mathrm{M}$ and $10 \mathrm{ng} / \mathrm{mL}$ TRAIL, 48 h), Figure S10: Phosphatidylserine externalization analysis gating strategy example (HCT 116, normoxia, Control, 48 h), Figure S11: Phosphatidylserine externalization analysis gating strategy example (HCT 116, normoxia, $10 \mathrm{ng} / \mathrm{mL}$ TRAIL, 48 h), Figure S12: Phosphatidylserine externalization analysis gating strategy example (HCT 116, normoxia, $10 \mu \mathrm{M} \mathrm{SKR,} 48$ h), Figure S13: Phosphatidylserine externalization analysis gating strategy example (HCT 116, normoxia, $10 \mu \mathrm{M}$ and $10 \mathrm{ng} / \mathrm{mL}$ TRAIL, 48 h), Figure S14: Phosphatidylserine externalization analysis gating strategy example (HT-29, hypoxia, Control, $48 \mathrm{~h}$ ), Figure S15: Phosphatidylserine externalization analysis gating strategy example (HT-29, hypoxia, $50 \mathrm{ng} / \mathrm{mL}$ TRAIL, 48 h), Figure S16: Phosphatidylserine externalization analysis gating strategy example (HT-29, hypoxia, $10 \mu \mathrm{M} \mathrm{SKR}, 48 \mathrm{~h}$ ), Figure S17: Phosphatidylserine externalization analysis gating strategy example (HT-29, hypoxia, $10 \mu \mathrm{M}$ and $50 \mathrm{ng} / \mathrm{mL}$ TRAIL, $48 \mathrm{~h}$ ), Figure S18: Phosphatidylserine externalization analysis gating strategy example (HT-29, normoxia, Control, $48 \mathrm{~h}$ ), Figure S19: Phosphatidylserine externalization analysis gating strategy example (HT-29, normoxia, $50 \mathrm{ng} / \mathrm{mL}$ TRAIL, $48 \mathrm{~h}$ ), Figure S20: Phosphatidylserine externalization analysis gating strategy example (HT-29, normoxia, $10 \mu \mathrm{M}$ SKR, 48 h), Figure S21: Phosphatidylserine externalization analysis gating strategy example (HT-29, normoxia, $10 \mu \mathrm{M}$ and $50 \mathrm{ng} / \mathrm{mL}$ TRAIL, $48 \mathrm{~h}$ ), Figure S22: Phosphatidylserine externalization analysis gating strategy example (SW620, hypoxia, Control, $48 \mathrm{~h}$ ), Figure S23: Phosphatidylserine externalization analysis gating strategy example (SW620, hypoxia, $50 \mathrm{ng} / \mathrm{mL}$ TRAIL, 48 h), Figure S24: Phosphatidylserine externalization analysis gating strategy example (SW620, hypoxia, $10 \mu \mathrm{M}$ SKR, 48 h), Figure S25: Phosphatidylserine externalization analysis gating strategy example (SW620, hypoxia, $10 \mu \mathrm{M}$ and $50 \mathrm{ng} / \mathrm{mL}$ TRAIL, 48 h), Figure S26: Phosphatidylserine externalization analysis gating strategy example (SW620, normoxia, Control, $48 \mathrm{~h}$ ), Figure S27: Phosphatidylserine externalization analysis gating strategy example (SW620, normoxia, $50 \mathrm{ng} / \mathrm{mL}$ TRAIL, 48 h), Figure S28: Phosphatidylserine externalization analysis gating strategy example (SW620, normoxia, $10 \mu \mathrm{M}$ SKR, 48 h), Figure S29: Phosphatidylserine externalization analysis gating strategy example (SW620, normoxia, $10 \mu \mathrm{M}$ and $50 \mathrm{ng} / \mathrm{mL}$ TRAIL, $48 \mathrm{~h}$ ), Figure S30: Cell cycle analysis gating strategy example (HCT 116, normoxia, Control, 48 h), Figure S31: Cell cycle analysis gating strategy example HCT 116, normoxia, $10 \mu \mathrm{M} \mathrm{SKR}, 48$ h, Figure S32: Cell cycle analysis gating strategy example HCT 116, hypoxia, Control, 48 h, Figure S33: Cell cycle analysis gating strategy example HCT 116, hypoxia, $10 \mu \mathrm{M}$ SKR, 48 h, Figure S34: Cell cycle analysis gating strategy example HT-29, normoxia, Control, 48 h, Figure S35: Cell cycle analysis gating strategy example HT-29, normoxia, $10 \mu \mathrm{M}$ SKR, 48 h, Figure S36: Cell cycle analysis gating strategy example HT-29, hypoxia, Control, $48 \mathrm{~h}$, Figure S37: Cell cycle analysis gating strategy example HT-29, hypoxia, $10 \mu \mathrm{M}$ SKR, 48 h, Figure S38: Melt curve after of the TNFRSF10B (DR5-both isoforms) gene fragment amplified in RT-qPCR by oligonucleotide primers DR5_for and DR5_rev, Figure S39: Melt curve after of the TNFRSF10B (DR5-isoform 1) gene fragment amplified in RT-qPCR by oligonucleotide primers DR5.v1_for and DR5.v1_rev, Figure S40: Melt curve after of the TNFRSF10B (DR5-isoform 2) gene fragment amplified in RT-qPCR by oligonucleotide primers DR5.v2_for and DR5.v2_rev, Figure S41: Melt curve after of the TNFRSF10A (DR4) gene fragment amplified in RT-qPCR by 
oligonucleotide primers DR4_for and DR4_rev, Figure S42: Melt curve after of the TNF (TNF alpha) gene fragment amplified in RT-qPCR by oligonucleotide primers TNF_for and TNF_rev, Figure S43: Melt curve after of the TNFRSF1A (TNFR1) gene fragment amplified in RT-qPCR by oligonucleotide primers TNFRSF1A_for and TNFRSF1A_rev, Figure S44: Melt curve after of the TNFRSF1B (TNFR2) gene fragment amplified in RT-qPCR by oligonucleotide primers TNFRSF1B_for and TNFRSF1B_rev, Figure S45: Melt curve after of the TNFRSF6B (DcR3) gene fragment amplified in RT-qPCR by oligonucleotide primers DcR3_for and DcR3_rev, Figure S46: Melt curve after of the PMM1 gene fragment, reference gene, amplified in RT-qPCR by oligonucleotide primers PMM1_for and PMM1_rev.

Author Contributions: M.B., R.J., J.V. and P.F. conceived and designed the study. M.B., R.J., M.M., J.K., K.M. performed the experiments. M.B. analyzed and interpreted data and performed the statistical analysis. M.B. wrote and prepared the original draft. R.J., J.V., Z.Z. and P.F performed formal analyses. All authors have read and agreed to the published version of the manuscript.

Funding: This research was supported by the Slovak Research and Development Agency (APVV18-0125), the Scientific Grant Agency of the Ministry of Education of the Slovak Republic (VEGA 1/0022/19), the Medical University Science Park in Košice (MediPark, Košice, ITMS 26220220185) and MediPark, Košice-Phase II (ITMS2014+: 313011D103) supported by the Operational Program Research and Development Program, funded by the ERDF. Measurements at Proteomics Core Facility CEITEC MU Brno, Czech Republic were supported by the projects CEITEC 2020 (LQ1601) and CIISB research infrastructure project LM2018127 and LM2015043 funded by MEYS CR. Computational resources were supplied by the project "e-Infrastruktura CZ" (e-INFRA LM2018140) provided within the program Projects of Large Research, Development and Innovations Infrastructures. The APC was funded by the Slovak Research and Development Agency (APVV-18-0125).

Institutional Review Board Statement: Not applicable.

Informed Consent Statement: Not applicable.

Data Availability Statement: Mass spectrometry data are available via ProteomeXchange with identifier PXD019995.

Acknowledgments: The authors are very grateful to Viera Balážová (UPJŠ Košice, Slovakia) and Danuše Fridrichová (CEITEC Brno, Czech Republic) for assistance with technical procedures and to Mária Babinčáková for proofreading the manuscript.

Conflicts of Interest: The authors declare no conflict of interest. The funders had no role in the design of the study; in the collection, analyses, or interpretation of data; in the writing of the manuscript, or in the decision to publish the results.

\section{Abbreviations}

The following abbreviations are used in this manuscript:

ABCG2 ATP-binding cassette super-family G member 2

DMSO Dimethylsulfoxid

DR5 Death receptor 5; known as TNFRSF10B (Tumor necrosis factor receptor superfamily 10B)

DTT Dithiothreitol

FACS Fluorescence-activated cell sorting

FDR False discovery rate

GN gene name

IC50 Half maximal inhibitory concentration

LC-MS Liquid chromatography-mass spectrometry

MTT 3-(4,5-dimethylthiazol-2-yl)-2,5-diphenyltetrazolium bromide

PBS Phosphate-buffered saline

PTEN Phosphatase and tensin homolog

RT-qPCR Reverse transcription quantitative polymerase chain reaction

SDS Sodium dodecyl sulfate

SKR Skyrin

TNF Tumor necrosis factor

TRAIL TNF-related apoptosis-inducing ligand 


\section{References}

1. Jahn, L.; Schafhauser, T.; Wibberg, D.; Rückert, C.; Winkler, A.; Kulik, A.; Weber, T.; Flor, L.; van Pée, K.H.; Kalinowski, J.; et al. Linking secondary metabolites to biosynthesis genes in the fungal endophyte Cyanodermella asteris: The anti-cancer bisanthraquinone skyrin. J. Biotechnol. 2017, 257, 233-239. [CrossRef] [PubMed]

2. Kimáková, K.; Kimáková, A.; Idkowiak, J.; Stobiecki, M.; Rodziewicz, P.; Marczak, Ł.; Čellárová, E. Phenotyping the genus Hypericum by secondary metabolite profiling: Emodin vs. skyrin, two possible key intermediates in hypericin biosynthesis. Anal. Bioanal. Chem. 2018, 410, 7689-7699. [CrossRef]

3. Rizzo, P.; Altschmied, L.; Stark, P.; Rutten, T.; Gündel, A.; Scharfenberg, S.; Franke, K.; Bäumlein, H.; Wessjohann, L.; Koch, M.; et al. Discovery of key regulators of dark gland development and hypericin biosynthesis in St. John's Wort (Hypericum perforatum). Plant Biotechnol. J. 2019, 17, 2299-2312. [CrossRef] [PubMed]

4. Howard, B.H.; Raistrick, H. Studies in the biochemistry of micro-organisms. 91. The colouring matters of Penicillium islandicum Sopp. Part 3. Skyrin and flavoskyrin. Biochem. J. 1954, 56, 56-65. [CrossRef]

5. Shibata, S.; Shoji, J.; Ohta, A.; Watanabe, M. Metabolic products of fungi. XI. Some observation on the occurrence of skyrin and rugulosin in mold metabolites, with a reference to structural relationship between penicilliopsin and skyrin. Pharm. Bull. 1957, 5, 380-382. [CrossRef] [PubMed]

6. Yanagi, Y.; Nakata, M.; Suzuki, N. Selective Inhibition of Viral RNA Transcription by Skyrin. J. Pestic. Sci. 1976, 1, 107-114. [CrossRef]

7. Kiyoshi, K.; Taketoshi, K.; Hideki, M.; Jiro, K.; Yoshinori, N. A comparative study on cytotoxicities and biochemical properties of anthraquinone mycotoxins emodin and skyrin from Penicillium islandicum sopp. Toxicol. Lett. 1984, 20, 155-160. [CrossRef]

8. Ueno, Y.; Umemori, K.; Niimi, E.C.C.; Tanuma, S.I.I.; Nagata, S.; Sugamata, M.; Ihara, T.; Sekijima, M.; Kawai, K.I.I.; Ueno, I.; et al. Induction of apoptosis by T-2 toxin and other natural toxins in HL-60 human promyelotic leukemia cells. Nat. Toxins 1995, 3, 129-137. [CrossRef] [PubMed]

9. Brady, S.F.; Singh, M.P.; Janso, J.E.; Clardy, J. Cytoskyrins A and B, new BIA active bisanthraquinones isolated from an endophytic fungus. Org. Lett. 2000, 2, 4047-4049. [CrossRef]

10. Parker, J.C.; McPherson, R.K.; Andrews, K.M.; Levy, C.B.; Dubins, J.S.; Chin, J.E.; Perry, P.V.; Hulin, B.; Perry, D.A.; Inagaki, T.; et al. Effects of skyrin, a receptor-selective glucagon antagonist, in rat and human hepatocytes. Diabetes 2000, 49, 2079-2086. [CrossRef]

11. Lin, L.C.; Chou, C.J.; Kuo, Y.C. Cytotoxic principles from Ventilago leiocarpa. J. Nat. Prod. 2001, 64, 674-676. [CrossRef] [PubMed]

12. Watts, P.; Kittakoop, P.; Veeranondha, S.; Wanasith, S.; Thongwichian, R.; Saisaha, P.; Intamas, S.; Hywel-Jones, N.L. Cytotoxicity against insect cells of entomopathogenic fungi of the genera Hypocrella (anamorph Aschersonia): Possible agents for biological control. Mycol. Res. 2003, 107, 581-586. [CrossRef] [PubMed]

13. Nicolaou, K.C.; Papageorgiou, C.D.; Piper, J.L.; Chadha, R.K. The cytoskyrin cascade: A facile entry into cytoskyrin A, deoxyrubroskyrin, rugulin, skyrin, and flavoskyrin model systems. Angew. Chemie Int. Ed. 2005, 44, 5846-5851. [CrossRef] [PubMed]

14. Vargas, F.; Rivas, C.; Zoltan, T.; Lopez, V.; Ortega, J.; Izzo, C.; Pineda, M.; Medina, J.; Medina, E.; Rosales, L. Antioxydant and scavenging activity of skyrin on free radical and some reactive oxygen species. Av. Quim. 2008, 3, 7-14.

15. Bräse, S.; Gläser, F.; Kramer, C.; Lindner, S.; Linsenmeier, A.M.; Masters, K.S.; Meister, A.C.; Ruff, B.M.; Zhong, S. The Chemistry of Mycotoxins; Progress in the Chemistry of Organic Natural Products; Springer: Vienna, Austria, 2013; Volume 97, pp. 139-151. [CrossRef]

16. Koul, M.; Meena, S.; Kumar, A.; Sharma, P.R.; Singamaneni, V.; Riyaz-Ul-Hassan, S.; Hamid, A.; Chaubey, A.; Prabhakar, A.; Gupta, P.; et al. Secondary Metabolites from Endophytic Fungus Penicillium pinophilum Induce ROS-Mediated Apoptosis through Mitochondrial Pathway in Pancreatic Cancer Cells. Planta Med. 2016, 82, 344-355. [CrossRef] [PubMed]

17. Revuru, B.; Bálintová, M.; Henzelyová, J.; Čellárová, E.; Kusari, S. MALDI-HRMS Imaging Maps the Localization of Skyrin, the Precursor of Hypericin, and Pathway Intermediates in Leaves of Hypericum Species. Molecules 2020, 25. [CrossRef]

18. Hatfield, G.; Slagle, D. Isolation of Skyrin from Hypomyces lactifluorum. Lloydia 1973, 36, 354-356.

19. Bara, R.A. Natural Products from Endophytic Fungus Talaromyces Wortmannii: Their Structure Elucidation and Mechanism of Actions. Ph.D. Thesis, Heinrich-Heine Universität Düsseldorf, Düsseldorf, Germany, 2012.

20. Bara, R.; Aly, A.H.; Pretsch, A.; Wray, V.; Wang, B.; Proksch, P.; Debbab, A. Antibiotically active metabolites from Talaromyces wortmannii, an endophyte of Aloe vera. J. Antibiot. 2013, 66, 491-493. [CrossRef] [PubMed]

21. Wang, C.; Jin, Q.; Yang, S.; Zhang, D.; Wang, Q.; Li, J.; Song, S.; Sun, Z.; Ni, Y.; Zhang, J.; et al. Synthesis and Evaluation of 131I-Skyrin as a Necrosis Avid Agent for Potential Targeted Radionuclide Therapy of Solid Tumors. Mol. Pharm. 2016, 13, 180-189. [CrossRef]

22. Zaman, A. Docking studies and network analyses reveal capacity of compounds from Kandelia rheedii to strengthen cellular immunity by interacting with host proteins during tuberculosis infection. Bioinformation 2012, 8, 1012-1020. [CrossRef]

23. Jendželovská, Z.; Jendželovský, R.; Hilovská, L.; Koval, J.; Mikeš, J.; Fedoročko, P. Single pre-treatment with hypericin, a St. John's wort secondary metabolite, attenuates cisplatin- and mitoxantrone-induced cell death in A2780, A2780cis and HL-60 cells. Toxicol. Vitr. 2014, 28, 1259-1273. [CrossRef]

24. Jendzelovská, Z.; Jendželovský, R.; Kuchárová, B.; Fedoročko, P. Hypericin in the Light and in the Dark: Two Sides of the Same Coin. Front. Plant Sci. 2016, 7, 1-20. [CrossRef] 
25. Hockel, M.; Vaupel, P. Tumor Hypoxia: Definitions and Current Clinical, Biologic, and Molecular Aspects. JNCI J. Natl. Cancer Inst. 2001, 93, 266-276. [CrossRef] [PubMed]

26. Muz, B.; de la Puente, P.; Azab, F.; Azab, A.K. The role of hypoxia in cancer progression angiogenesis metastasis and resistane to therapy. Hypoxia 2015, 3, 83-92. [CrossRef] [PubMed]

27. Dang, C.V.; Semenza, G.L. Oncogenic alterations of metabolism. Trends Biochem. Sci. 1999, 24, 68-72. [CrossRef]

28. Challapalli, A.; Carroll, L.; Aboagye, E.O. Molecular mechanisms of hypoxia in cancer. Clin. Transl. Imaging 2017, 5, 225-253. [CrossRef] [PubMed]

29. Wang, G.L.; Jiang, B.H.; Rue, E.A.; Semenza, G.L. Hypoxia-inducible factor 1 is a basic-helix-loop-helix-PAS heterodimer regulated by cellular O2 tension. Proc. Natl. Acad. Sci. USA 1995, 92, 5510-5514. [CrossRef]

30. Wang, G.L.; Semenza, G.L. Purification and Characterization of Hypoxia-inducible Factor 1. J. Biol. Chem. 1995, $270,1230-1237$. [CrossRef] [PubMed]

31. Semenza, G.L. Targeting HIF-1 for cancer therapy. Nat. Rev. Cancer 2003, 3, 721-732. [CrossRef]

32. Rademakers, S.E.; Span, P.N.; Kaanders, J.H.A.M.; Sweep, F.C.G.J.; van der Kogel, A.J.; Bussink, J. Molecular aspects of tumour hypoxia. Mol. Oncol. 2008, 2, 41-53. [CrossRef]

33. Vaupel, P. The Role of Hypoxia-Induced Factors in Tumor Progression. Oncologist 2004, 9, 10-17. [CrossRef]

34. Abraham, J.; Salama, N.N.; Azab, A.K. The role of P-glycoprotein in drug resistance in multiple myeloma Leuk. Lymphoma 2015, 56, 26-33. [CrossRef] [PubMed]

35. Das, B.; Tsuchida, R.; Malkin, D.; Koren, G.; Baruchel, S.; Yeger, H. Hypoxia Enhances Tumor Stemness by Increasing the Invasive and Tumorigenic Side Population Fraction. Stem Cells 2008, 26, 1818-1830. [CrossRef] [PubMed]

36. Duiker, E.W.; Mom, C.H.; de Jong, S.; Willemse, P.H.; Gietema, J.A.; van der Zee, A.G.; de Vries, E.G. The clinical trail of TRAIL. Eur. J. Cancer 2006, 42, 2233-2240. [CrossRef] [PubMed]

37. Stolfi, C.; Pallone, F.; Monteleone, G. Molecular Targets of TRAIL-Sensitizing Agents in Colorectal Cancer. Int. J. Mol. Sci. 2012, 13, 7886-7901. [CrossRef]

38. Szliszka, E.; Zydowicz, G.; Mizgala, E.; Krol, W. Artepillin C (3,5-diprenyl-4-hydroxycinnamic acid) sensitizes LNCaP prostate cancer cells to TRAIL-induced apoptosis. Int. J. Oncol. 2012, 41, 818-828. [CrossRef] [PubMed]

39. Cormier, Z. Small-molecule drug drives cancer cells to suicide. Nature 2013. [CrossRef]

40. Mahajan, S.; Dammai, V.; Hsu, T.; Kraft, A. Hypoxia-inducible factor- $2 \alpha$ regulates the expression of TRAIL receptor DR5 in renal cancer cells. Carcinogenesis 2008, 29, 1734-1741. [CrossRef]

41. Kim, M.; Park, S.Y.; Pai, H.S.; Kim, T.H.; Billiar, T.R.; Seol, D.W. Hypoxia inhibits tumor necrosis factor-related apoptosis-inducing ligand-induced apoptosis by blocking Bax translocation. Cancer Res. 2004, 64, 4078-4081. [CrossRef] [PubMed]

42. Nagaraj, N.S.; Vigneswaran, N.; Zacharias, W. Hypoxia inhibits TRAIL-induced tumor cell apoptosis: Involvement of lysosomal cathepsins. Apoptosis 2007, 12, 125-139. [CrossRef] [PubMed]

43. Guo, L.; Fan, L.; Ren, J.; Pang, Z.; Ren, Y.; Li, J.; Wen, Z.; Jiang, X. A novel combination of TRAIL and doxorubicin enhances antitumor effect based on passive tumor-targeting of liposomes. Nanotechnology 2011, 22, 265105. [CrossRef] [PubMed]

44. Jung, K.A.; Choi, B.H.; Kwak, M.K. The c-MET/PI3K signaling is associated with cancer resistance to doxorubicin and photodynamic therapy by elevating BCRP/ABCG2 expression. Mol. Pharmacol. 2015, 87, 465-476. [CrossRef]

45. Subramaniam, A.; Loo, S.Y.; Rajendran, P.; Manu, K.A.; Perumal, E.; Li, F.; Shanmugam, M.K.; Siveen, K.S.; Park, J.I.; Ahn, K.S.; et al. An anthraquinone derivative, emodin sensitizes hepatocellular carcinoma cells to TRAIL induced apoptosis through the induction of death receptors and downregulation of cell survival proteins. Apoptosis 2013, 18, 1175-1187. [CrossRef] [PubMed]

46. Todo, M.; Horinaka, M.; Tomosugi, M.; Tanaka, R.; Ikawa, H.; Sowa, Y.; Ishikawa, H.; Fujiwara, H.; Otsuji, E.; Sakai, T. Ibuprofen enhances TRAIL-induced apoptosis through DR5 upregulation. Oncol. Rep. 2013, 30, 2379-2384. [CrossRef] [PubMed]

47. Senbabaoglu, F.; Cingoz, A.; Kaya, E.; Kazancioglu, S.; Lack, N.A.; Acilan, C.; Bagci-Onder, T. Identification of Mitoxantrone as a TRAIL-sensitizing agent for Glioblastoma Multiforme. Cancer Biol. Ther. 2016, 17, 546-557. [CrossRef] [PubMed]

48. Petrova, V.; Annicchiarico-Petruzzelli, M.; Melino, G.; Amelio, I. The hypoxic tumour microenvironment. Oncogenesis 2018. [CrossRef]

49. Majerník, M.; Jendželovský, R.; Babinčák, M.; Košuth, J.; Ševc, J.; Tonelli Gombalová, Z.; Jendželovská, Z.; Buríková, M.; Fedoročko, P. Novel Insights into the Effect of Hyperforin and Photodynamic Therapy with Hypericin on Chosen Angiogenic Factors in Colorectal Micro-Tumors Created on Chorioallantoic Membrane. Int. J. Mol. Sci. 2019, 20, 3004. [CrossRef]

50. Xu, K.; Zhan, Y.; Yuan, Z.; Qiu, Y.; Wang, H.; Fan, G.; Wang, J.; Li, W.; Cao, Y.; Shen, X.; et al. Hypoxia Induces Drug Resistance in Colorectal Cancer through the HIF-1 $\alpha /$ miR-338-5p/IL-6 Feedback Loop. Mol. Ther. 2019, 27, 1810-1824. [CrossRef]

51. Knoll, G.; Bittner, S.; Kurz, M.; Jantsch, J.; Ehrenschwender, M. Hypoxia regulates TRAIL sensitivity of colorectal cancer cells through mitochondrial autophagy. Oncotarget 2016, 7, 41488-41504. [CrossRef]

52. Yao, K.; Gietema, J.A.; Shida, S.; Selvakumaran, M.; Fonrose, X.; Haas, N.B.; Testa, J.; O’Dwyer, P.J. In vitro hypoxia-conditioned colon cancer cell lines derived from HCT116 and HT29 exhibit altered apoptosis susceptibility and a more angiogenic profile in vivo. Br. J. Cancer 2005, 93, 1356-1363. [CrossRef]

53. Bunz, F.; Hwang, P.M.; Torrance, C.; Waldman, T.; Zhang, Y.; Dillehay, L.; Williams, J.; Lengauer, C.; Kinzler, K.W.; Vogelstein, B. Disruption of p53 in human cancer cells alters the responses to therapeutic agents. J. Clin. Investig. 1999, 104, 263-269. [CrossRef] [PubMed] 
54. Zhang, L.; Yu, J.; Park, B.H.; Kinzler, K.W.; Vogelstein, B. Role of BAX in the apoptotic response to anticancer agents. Science 2000, 290, 989-992. [CrossRef] [PubMed]

55. Aires, V.; Colin, D.J.; Doreau, A.; Di Pietro, A.; Heydel, J.M.; Artur, Y.; Latruffe, N.; Delmas, D. P-Glycoprotein 1 Affects Chemoactivities of Resveratrol against Human Colorectal Cancer Cells. Nutrients 2019, 11, 2098. [CrossRef] [PubMed]

56. Jendželovský, R.; Mikeš, J.; Koval', J.; Souček, K.; Procházková, J.; Kello, M.; Sačková, V.; Hofmanová, J.; Kozubík, A.; Fedoročko, P. Drug efflux transporters, MRP1 and BCRP, affect the outcome of hypericin-mediated photodynamic therapy in HT-29 adenocarcinoma cells. Photochem. Photobiol. Sci. 2009, 8, 1716-1723. [CrossRef]

57. Jendželovský, R.; Jendželovská, Z.; Kuchárová, B.; Fedoročko, P. Breast cancer resistance protein is the enemy of hypericin accumulation and toxicity of hypericin-mediated photodynamic therapy. Biomed. Pharmacother. 2019, 109, 2173-2181. [CrossRef]

58. Vargová, J.; Mikeš, J.; Jendželovský, R.; Mikešová, L.; Kuchárová, B.; Čulka, L.; Fedr, R.; Remšík, J.; Souček, K.; Kozubík, A.; et al. Hypericin affects cancer side populations via competitive inhibition of BCRP. Biomed. Pharmacother. 2018, 99, 511-522. [CrossRef]

59. Doyle, L.A.; Ross, D.D. Multidrug resistance mediated by the breast cancer resistance protein BCRP (ABCG2). Oncogene 2003, 22, 7340-7358. [CrossRef]

60. Rosenberg, M.F.; Bikadi, Z.; Chan, J.; Liu, X.; Ni, Z.; Cai, X.; Ford, R.C.; Mao, Q. The Human Breast Cancer Resistance Protein (BCRP/ABCG2) Shows Conformational Changes with Mitoxantrone. Structure 2010, 18, 482-493. [CrossRef]

61. Fetsch, P.A.; Abati, A.; Litman, T.; Morisaki, K.; Honjo, Y.; Mittal, K.; Bates, S.E. Localization of the ABCG2 mitoxantrone resistance-associated protein in normal tissues. Cancer Lett. 2006, 235, 84-92. [CrossRef]

62. Hilovska, L.; Jendželovský, R.; Jendželovská, Z.; Koval', J.; Fedoročko, P. Downregulation of BCRP and anti-apoptotic proteins by proadifen (SKF-525A) is responsible for the enhanced mitoxantrone accumulation and toxicity in mitoxantrone-resistant human promyelocytic leukemia cells. Int. J. Oncol. 2015, 47, 1572-1584. [CrossRef]

63. He, X.; Wang, J.; Wei, W.; Shi, M.; Xin, B.; Zhang, T.; Shen, X. Hypoxia regulates ABCG2 activity through the activivation of ERK1/2/HIF- $1 \alpha$ and contributes to chemoresistance in pancreatic cancer cells. Cancer Biol. Ther. 2016, 17, 188-198. [CrossRef]

64. Martin, C.M.; Ferdous, A.; Gallardo, T.; Humphries, C.; Sadek, H.; Caprioli, A.; Garcia, J.A.; Szweda, L.I.; Garry, M.G.; Garry, D.J. Hypoxia-Inducible Factor- $2 \alpha$ Transactivates Abcg 2 and Promotes Cytoprotection in Cardiac Side Population Cells. Circ. Res. 2008, 102, 1075-1081. [CrossRef]

65. Jing, X.; Yang, F.; Shao, C.; Wei, K.; Xie, M.; Shen, H.; Shu, Y. Role of hypoxia in cancer therapy by regulating the tumor microenvironment. Mol. Cancer 2019, 18, 1-15. [CrossRef]

66. Triner, D.; Shah, Y.M. Hypoxia-inducible factors: A central link between inflammation and cancer. J. Clin. Investig. 2016, 126, 3689-3698. [CrossRef]

67. Seo, S.B.; Hur, J.G.; Kim, M.J.; Lee, J.W.; Kim, H.B.; Bae, J.H.; Kim, D.W.; Kang, C.D.; Kim, S.H. TRAIL sensitize MDR cells to MDR-related drugs by down-regulation of P-glycoprotein through inhibition of DNA-PKcs/Akt/GSK-3 $\beta$ pathway and activation of caspases. Mol. Cancer 2010, 9, 199. [CrossRef]

68. Sadarangani, A.; Kato, S.; Espinoza, N.; Lange, S.; Llados, C.; Espinosa, M.; Villalón, M.; Lipkowitz, S.; Cuello, M.; Owen, G.I. TRAIL mediates apoptosis in cancerous but not normal primary cultured cells of the human reproductive tract. Apoptosis 2007, 12, 73-85. [CrossRef]

69. Van Dijk, M.; Halpin-McCormick, A.; Sessler, T.; Samali, A.; Szegezdi, E. Resistance to TRAIL in non-transformed cells is due to multiple redundant pathways. Cell Death Dis. 2013, 4, e702. [CrossRef]

70. Huang, Y.; Yang, X.; Xu, T.; Kong, Q.; Zhang, Y.; Shen, Y.; Wei, Y.; Wang, G.; Chang, K.J. Overcoming resistance to TRAIL-induced apoptosis in solid tumor cells by simultaneously targeting death receptors, c-FLIP and IAPs. Int. J. Oncol. 2016, 49, 153-163. [CrossRef]

71. Kretz, A.L.; Trauzold, A.; Hillenbrand, A.; Knippschild, U.; Henne-Bruns, D.; von Karstedt, S.; Lemke, J. Trailblazing strategies for cancer treatment. Cancers 2019, 11, 456. [CrossRef]

72. Zhang, B.; Liu, B.; Chen, D.; Setroikromo, R.; Haisma, H.J.; Quax, W.J. Histone Deacetylase Inhibitors Sensitize TRAIL-Induced Apoptosis in Colon Cancer Cells. Cancers 2019, 11, 645. [CrossRef] [PubMed]

73. Sophonnithiprasert, T.; Nilwarangkoon, S.; Nakamura, Y.; Watanapokasin, R. Goniothalamin enhances TRAIL-induced apoptosis in colorectal cancer cells through DR5 upregulation and cFLIP downregulation. Int. J. Oncol. 2015, 47, 2188-2196. [CrossRef]

74. Chen, M.; Wang, X.; Zha, D.; Cai, F.; Zhang, W.; He, Y.; Huang, Q.; Zhuang, H.; Hua, Z.C. Apigenin potentiates TRAIL therapy of non-small cell lung cancer via upregulating DR4/DR5 expression in a p53-dependent manner. Sci. Rep. 2016, 6, 35468. [CrossRef]

75. Yao, Z.; Chen, A.; Li, X.; Zhu, Z.; Jiang, X. Hsp90 inhibitor sensitizes TRAIL-mediated apoptosis via chop-dependent DR5 upregulation in colon cancer cells. Am. J. Transl. Res. 2017, 9, 4945. [PubMed]

76. Rasheduzzaman, M.; Jeong, J.K.; Park, S.Y. Resveratrol sensitizes lung cancer cell to TRAIL by p53 independent and suppression of Akt/NF- $\kappa$ B signaling. Life Sci. 2018, 208, 208-220. [CrossRef] [PubMed]

77. Dilshara, M.G.; Molagoda, I.M.N.; Jayasooriya, R.G.P.T.; Choi, Y.H.; Park, C.; Lee, K.T.; Lee, S.; Kim, G.Y. P53-mediated oxidative stress enhances indirubin-3 -monoxime-induced apoptosis in HCT116 colon cancer cells by upregulating death receptor 5 and TNF-related apoptosis-inducing ligand expression. Antioxidants 2019, 8. [CrossRef]

78. Na, Y.J.; Lee, D.H.; Kim, J.L.; Kim, B.R.; Park, S.H.; Jo, M.J.; Jeong, S.; Kim, H.J.; young Lee, S.; Jeong, Y.A.; et al. Cyclopamine sensitizes TRAIL-resistant gastric cancer cells to TRAIL-induced apoptosis via endoplasmic reticulum stress-mediated increase of death receptor 5 and survivin degradation. Int. J. Biochem. Cell Biol. 2017, 89, 147-156. [CrossRef] 
79. Schempp, C.M.; Simon-Haarhaus, B.; Termeer, C.C.; Simon, J.C. Hypericin photo-induced apoptosis involves the tumor necrosis factor-related apoptosis-inducing ligand (TRAIL) and activation of caspase-8. FEBS Lett. 2001, 493, 26-30. [CrossRef]

80. Zhang, P.; Wang, H.; Chen, Y.; Lodhi, A.F.; Sun, C.; Sun, F.; Yan, L.; Deng, Y.; Ma, H. DR5 related autophagy can promote apoptosis in gliomas after irradiation. Biochem. Biophys. Res. Commun. 2020, 522, 910-916. [CrossRef]

81. Fagerberg, L.; Hallstrom, B.M.; Oksvold, P.; Kampf, C.; Djureinovic, D.; Odeberg, J.; Habuka, M.; Tahmasebpoor, S.; Danielsson, A.; Edlund, K.; et al. Analysis of the human tissue-specific expression by genome-wide integration of transcriptomics and antibody-based proteomics. Mol. Cell. Proteomics 2014, 13, 397-406. [CrossRef]

82. Hellwig, C.T.; Rehm, M. TRAIL signaling and synergy mechanisms used in TRAIL-based combination therapies. Mol. Cancer Ther. 2012, 11, 3-13. [CrossRef]

83. Falschlehner, C.; Emmerich, C.H.; Gerlach, B.; Walczak, H. TRAIL signalling: Decisions between life and death. Int. J. Biochem. Cell Biol. 2007, 39, 1462-1475. [CrossRef] [PubMed]

84. Mills, K.R.; Reginato, M.; Debnath, J.; Queenan, B.; Brugge, J.S. Tumor necrosis factor-related apoptosis-inducing ligand (TRAIL) is required for induction of autophagy during lumen formation in vitro. Proc. Natl. Acad. Sci. USA 2004, 101, 3438-3443. [CrossRef] [PubMed]

85. Pespeni, M.H.; Hodnett, M.; Abayasiriwardana, K.S.; Roux, J.; Howard, M.; Broaddus, V.C.; Pittet, J.F. Sensitization of mesothelioma cells to tumor necrosis factor-related apoptosis-inducing ligand-induced apoptosis by heat stress via the inhibition of the 3-phosphoinositide-dependent kinase 1/Akt pathway. Cancer Res. 2007, 67, 2865-2871. [CrossRef]

86. Li, L.; Wen, X.Z.; Bu, Z.D.; Cheng, X.J.; Xing, X.F.; Wang, X.H.; Zhang, L.H.; Guo, T.; Du, H.; Hu, Y.; et al. Paclitaxel enhances tumoricidal potential of TRAIL via inhibition of MAPK in resistant gastric cancer cells. Oncol. Rep. 2016, 35, 3009-3017. [CrossRef]

87. Fei, P.; Wang, W.; Kim, S.H.; Wang, S.; Burns, T.F.; Sax, J.K.; Buzzai, M.; Dicker, D.T.; McKenna, W.G.; Bernhard, E.J.; et al. Bnip3L is induced by p53 under hypoxia, and its knockdown promotes tumor growth. Cancer Cell 2004, 6, 597-609. [CrossRef]

88. Shao, C.; Li, Z.; Ahmad, N.; Liu, X. Regulation of PTEN degradation and NEDD4-1 E3 ligase activity by Numb. Cell Cycle 2017, 16, 957-967. [CrossRef]

89. Jouan-Lanhouet, S.; Arshad, M.I.; Piquet-Pellorce, C.; Martin-Chouly, C.; Le Moigne-Muller, G.; Van Herreweghe, F.; Takahashi, N.; Sergent, O.; Lagadic-Gossmann, D.; Vandenabeele, P.; et al. TRAIL induces necroptosis involving RIPK1/RIPK3-dependent PARP-1 activation. Cell Death Differ. 2012, 19, 2003-2014. [CrossRef]

90. Luebke, T.; Schwarz, L.; Beer, Y.Y.; Schumann, S.; Misterek, M.; Sander, F.E.; Plaza-Sirvent, C.; Schmitz, I. c-FLIP and CD95 signaling are essential for survival of renal cell carcinoma. Cell Death Dis. 2019, 10, 1-12. [CrossRef]

91. Cox, J.; Mann, M. MaxQuant enables high peptide identification rates, individualized p.p.b.-range mass accuracies and proteomewide protein quantification. Nat. Biotechnol. 2008, 26, 1367-1372. [CrossRef]

92. Cox, J.; Neuhauser, N.; Michalski, A.; Scheltema, R.A.; Olsen, J.V.; Mann, M. Andromeda: A Peptide Search Engine Integrated into the MaxQuant Environment. J. Proteome Res. 2011, 10, 1794-1805. [CrossRef]

93. Ye, J.; Coulouris, G.; Zaretskaya, I.; Cutcutache, I.; Rozen, S.; Madden, T.L. Primer-BLAST: A tool to design target-specific primers for polymerase chain reaction. BMC Bioinform. 2012, 13, 134. [CrossRef]

94. Okonechnikov, K.; Golosova, O.; Fursov, M.; Varlamov, A.; Vaskin, Y.; Efremov, I.; German Grehov, O.G.; Kandrov, D.; Rasputin, K.; Syabro, M.; et al. Unipro UGENE: A unified bioinformatics toolkit. Bioinformatics 2012, 28, 1166-1167. [CrossRef]

95. R Core Team. R: A Language and Environment for Statistical Computing; R Foundation for Statistical Computing: Vienna, Austria, 2020.

96. Venables, W.N.; Ripley, B.D. Modern Applied Statistics with S, 4th ed.; Springer: New York, NY, USA, 2002.

97. Wickham, H. Reshaping Data with the \{reshape\} Package. J. Stat. Softw. 2007, 21, 1-20. [CrossRef]

98. Sarkar, D. Lattice: Multivariate Data Visualization with R; Springer: New York, NY, USA, 2008.

99. Clark, N.; Hafner, M.; Kouril, M.; Muhlich, J.; Niepel, M.; Williams, E.; Sorger, P.; Medvedovic, M. GRcalculator: An online tool for calculating and mining drug response data. BMC Cancer 2017. [CrossRef]

100. Wickham, H. ggplot2: Elegant Graphics for Data Analysis; Springer: New York, NY, USA, 2016.

101. Auguie, B. Miscellaneous Functions for "Grid" Graphics; R Foundation for Statistical Computing: Vienna, Austria, 2017.

102. Sievert, C. Plotly for R; R Foundation for Statistical Computing: Vienna, Austria, 2018.

103. Xiao, N. ggsci: Scientific Journal and Sci-Fi Themed Color Palettes for 'ggplot2'; R Foundation for Statistical Computing: Vienna, Austria, 2018.

104. Wickham, H.; Averick, M.; Bryan, J.; Chang, W.; McGowan, L.D.; François, R.; Grolemund, G.; Hayes, A.; Henry, L.; Hester, J.; et al. Welcome to the \{tidyverse\}. J. Open Source Softw. 2019, 4, 1686. [CrossRef]

105. Wickham, H.; François, R.; Henry, L.; Müller, K. Dplyr: A Grammar of Data Manipulation; R Foundation for Statistical Computing: Vienna, Austria, 2020.

106. R Core Team. Foreign: Read Data Stored by 'Minitab', 'S', 'SAS', 'SPSS', 'Stata', 'Systat', 'Weka', 'dBase', ...; R Foundation for Statistical Computing: Vienna, Austria, 2020.

107. Wickham, H.; Henry, L. Tidyr: Tidy Messy Data; R Foundation for Statistical Computing: Vienna, Austria, 2020.

108. Wickham, H. Forcats: Tools for Working with Categorical Variables (Factors); R Foundation for Statistical Computing: Vienna, Austria, 2020 . 